\title{
Mechanisms of cisplatin resistance and targeting of cancer stem cells: Adding glycosylation to the equation
}

\author{
José Alexandre Ferreira ${ }^{1,2,3,4^{*}}$, Andreia Peixoto ${ }^{1 *}$, Manuel Neves ${ }^{1 *}$, Cristiana Gaiteiro ${ }^{1}$, \\ Celso A. Reis ${ }^{3,4,5,6}$, Yehuda G. Assaraf ${ }^{7}$, Lúcio Lara Santos ${ }^{1,8,9}$
}

${ }^{1}$ Experimental Pathology and Therapeutics group, Portuguese Institute for Oncology of Porto, Porto, Portugal; ${ }^{2}$ Mass Spectrometry Center, QOPNA, Department of Chemistry of the University of Aveiro, Campus de Santiago, Aveiro, Portugal; ${ }^{3} \mathrm{i} 3 \mathrm{~S}$ - Instituto de Investigação e Inovação em Saúde, University of Porto, Portugal; 4Institute of Molecular Pathology and Immunology of the University of Porto (IPATIMUP), Porto, Portugal; ${ }^{5}$ Institute of Biomedical Sciences Abel Salazar (ICBAS), University of Porto, Porto, Portugal; ${ }^{6}$ Faculty of Medicine of the University of Porto, 4200-319 Porto, Portugal; ${ }^{7}$ The Fred Wyszkowski Cancer Research Laboratory, Dept. of Biology, Technion-Israel Institute of Technology, Haifa Israel; ${ }^{8}$ Health School of University of Fernando Pessoa, Porto, Portugal; ${ }^{9}$ Department of Surgical Oncology, Portuguese Institute for Oncology, Porto, Portugal.

*Equal contribution

Keywords: chemotherapy resistance; Cancer Stem cells; cancer therapy, protein glycosylation; cisplatin, epithelial-to- mesenchymal; cancer biomarkers

\section{Corresponding Author:}

José Alexandre Ferreira; e-mail: josealexandreferreira@ua.pt (cancer glycobiology) 
Lúcio Lara Santos; e-mail: 1larasantos@ gmail.com (cancer therapeutics)

\begin{abstract}
Cisplatin-based chemotherapeutic regimens are the most frequently used (neo)adjuvant treatments for the majority of solid tumors. While platinum-based chemotherapeutic regimens have proven effective against highly proliferative malignant tumors, significant relapse and progression rates as well as decreased overall survival are still observed. Currently, it is known that sub-populations of chemoresistant cells share biological properties with cancer stem cells (CSC), which are believed to be responsible for tumor relapse, invasion and ultimately disease dissemination through acquisition of mesenchymal cell traits. In spite of concentrated efforts devoted to decipher the mechanisms underlying CSC chemoresistance and to design targeted therapeutics to these cells, proteomics has failed to unveil molecular signatures capable of distinguishing between malignant and non-malignant stem cells. This has hampered substantial developments in this complex field. Envisaging a novel rationale for an effective therapy, the current review summarizes the main cellular and molecular mechanisms underlying cisplatin resistance and the impact of chemotherapy challenge in CSC selection and clinical outcome. It further emphasizes the growing amount of data supporting a role for protein glycosylation in drug resistance. The dynamic and context-dependent nature of protein glycosylation is also comprehensively discussed, hence highlighting its potentially important role as a biomarker of CSC. As the paradigm of cancer therapeutics shifts towards precision medicine and patient-tailored therapeutics, we bring into focus the need to introduce glycomics and glycoproteomics in holistic pan-omics models, in order to integrate diverse, multimodal and clinically relevant information towards more effective cancer therapeutics.
\end{abstract}

\title{
1. Introduction
}

Cisplatin (cis-diamminedichloridoplatinum(II); cis-[Pt( $\left.\left(\mathrm{NH}_{3}\right)_{2}(\mathrm{Cl})_{2}\right]$ ) was first described by Michele Peyrone in 1845, but its structure was only determined in 1893 (Trzaska S, 2005). After several years of investigation, Rosenberg realized its potential to induce tumor cells death (Rosenberg B, 1973) and finally in 1978 the drug was 
approved by the FDA for the treatment of testicular and ovarian cancer (Trzaska S, 2005). Nowadays, cisplatin-based regimens are widely used as (neo)adjuvant chemotherapy against a spectrum of solid tumors including gastric, non-small cell lung (NSCLC), head and neck, gallbladder, and urinary bladder cancer. However, cisplatin treatment exhibits severe side effects including immunosuppression, renal toxicity, gastrointestinal disorders and ototoxicity (Boussios S et al., 2012; Karasawa T et al., 2015). It may also cause gonadal suppression resulting in amenorrhea or azoospermia, partial or irreversible infertility and embryo-toxicity (Brennemann W et al., 1997; Meistrich ML, 2009).

Cisplatin is an alkylating agent capable of forming adducts with macromolecules, particularly with $\mathrm{N} 7$ atoms of purine nucleobases. This results in interand intra-strand DNA cross-links that bring induce cell cycle arrest mainly in the $G_{2} / M$ checkpoint (Yuan L et al., 2003). The inability to repair this DNA damage ultimately leads to programmed cell death. However, experimental evidence revealed that other mechanisms such as the production of reactive oxygen species (ROS) and the activation of inflammatory pathways, may also contribute to the induction of apoptosis (Casares $\mathrm{C}$ et al., 2012). Cisplatin has shown significant efficacy against rapidly proliferating tumor cells. However, despite a fairly acceptable intrinsic drug response rate, there is a $95 \%$ risk of tumor relapse in NSCLC patients. The 5-year survival rate is approximately $50 \%$ for muscle-invasive bladder cancer, (Nadal R et al., 2014) and 15-20\% for ovarian cancer patients (Siddik ZH, 2003); similar survival rates have been reported for other solid tumors. It has been hypothesized that chemotherapy may either act as a selective pressure for more aggressive cell phenotypes (Freitas DP et al., 2014), or that tumor cells which are less drug sensitive may acquire mutations during the course of treatment, that enable them to evade drug-induced cell death (Crea F et al., 2011). The failure of cisplatin-based regimens is considered both life-threatening and a major burden to health care systems, as it requires the introduction of more expensive second line treatments. Therefore, deciphering the mechanisms underlying this treatment failure has been a primary goal of cancer research and, in the past two decades, some of the modalities underlying anticancer drug resistance have been identified; however the implications for improving drug therapy have been limited.

Chemotherapy resistance results from a synergism of events that include tumor cell extrinsic factors (pharmacokinetic resistance and tumor microenvironment) as well 
as intrinsic factors, namely alterations in drug transport and metabolism, relative dormancy/slow cell cycle kinetics, efficient DNA repair systems and inhibition of apoptosis (Martin LP et al.; Pommier Y et al., 2004; Raguz S and Yague E, 2008). In addition, some chemoresistant tumor cell clones may present self-renewal and pluri/multipotent differentiation capabilities, which are characteristics associated with cancer-stem cells (CSC) (Visvader JE and Lindeman GJ, 2008). Therefore, these cells constitute a small pool of CSC capable of generating more differentiated subpopulations that, during subsequent divisions, form the vast majority of the tumor bulk. The remarkable longevity of CSC also renders them more susceptible to the accumulation of genetic damage and epigenetic alterations that may ultimately promote the proliferation of heterogeneous and aggressive cell phenotypes (Muñoz $\mathrm{P}$ et al., 2012). Some subsets of CSC can be found in poorly vascularized hypoxic tumor niches, which favour the maintenance of stem-cell characteristics, and are consequently exposed to suboptimal drug concentrations (Lin Q and Yun Z, 2010). Furthermore, these cells may undergo epithelial-to-mesenchymal transition (EMT) in response to microenvironmental stimuli, namely prolonged exposure to low oxygen levels, and may acquire the capability to invade and metastasize to regional lymph nodes and distant organs (Jiang $\mathbf{J}$ et al., 2011). In summary, it became evident that cisplatin and other conventional chemotherapeutic drugs may ultimately contribute to the selection of a pool of slow dividing or quiescent CSC (Wang W et al., 2014). These cells are endowed with the capability of recapitulating tumor heterogeneity and undergo EMT, considered as one of the driving forces of cancer dissemination (Frank NY et al., 2010). As such, patients would greatly benefit from combined therapies including agents capable of selectively eliminating CSC. The ideal therapy should specifically recognize these cells from the tumor bulk, include means to inhibit resistance mechanisms, as well as include CSC-killing agents. However, the majority of membrane-bound CSC biomarkers known to date can also be found in normal stem- and non-malignant cells (Cojoc $\mathrm{M}$ et al., 2015), which hampers the development of specific targeted therapeutics.

More recently, several studies have demonstrated that profound alterations in protein glycosylation that often accompany malignant transformation may also influence resistance to chemotherapy. This rather neglected mechanism of drug resistance has been often associated with impaired function of membrane-bound glycoproteins, such as ATP-binding cassette efflux transporters, due to specific 
alterations in their glycosylation patterns (Beers MF et al., 2013; Nakagawa H et al, 2009). However, alterations in cell-surface protein glycosylation have also been shown to favor oncogenic signaling pathways associated with chemoresistance and CSC-like phenotypes (Dall'Olio F et al., 2014; Häuselmann I and Borsig L, 2014; Ju T et al., 2008; Pinho SS et al., 2012). Therefore, cancer-associated glycans constitute markers of chemoresistance and bear potential promise for the identification and therapeutic targeting of CSC.

Envisaging a rationale for an effective therapy, the present review discusses the main mechanisms of cisplatin resistance known to date, integrating key insights about the role of cancer-associated glycans. Although the current review focuses mainly on cisplatin, it is proposed here that many of these strategies mediate resistance to other drugs as well. The present paper also provides a comprehensive overview on the impact of the chemotherapeutic challenge in tumor biology, CSC selection and clinical outcome. Moreover, it aims to raise awareness for the fact that CSC harbor distinct glycosylation patterns that should be carefully explored towards the development of highly specific targeted therapeutics.

\section{Overview on drug resistance mechanisms and CSC selection}

Drug resistance is a multifactorial process which is based on both extrinsic and intrinsic factors in tumor cells (Raguz S and Yague E, 2008). Extrinsic factors such as unfavorable drug pharmacokinetics and abnormal tumor vasculature result in the delivery of suboptimal concentrations of cytotoxic agents to tumor sites (Rohwer $\mathrm{N}$ et al, 2011). Defective tumor vasculature also results in hypoxic and acidic niches that significantly modulate cell function in manners that favor chemoresistance (Wilson WR and Hay MP, 2011). Similarly, alterations in the extracellular matrix architecture and stromal cell paracrine signals have been found to influence chemotherapy outcome (Sherman-Baust CA et al, 2003; Tripathi M et al., 2012). In addition, tumor cells may either present, or develop during the course of treatment, various mechanisms to withstand and overcome chemotherapeutic challenges (Shen D et al., 2012). These mechanisms include for example: i) Alterations in drug transport and metabolism; ii) Enhanced DNA repair mechanisms; iii) Alterations in cell cycle regulation; and iv) Inhibition of apoptosis. Emerging evidences support the notion that chemoresistance, 
driven by the above mentioned factors, is associated with CSC-like properties as well as the acquisition of EMT capability, thereby explaining the high relapse and progression rates presented by first line chemotherapy agents (Cojoc $\mathrm{M}$ et al., 2015). Based on these considerations, the following sections aim to illustrate the influence of the main tumorassociated extrinsic and intrinsic properties in chemoresistance.

\subsection{The impact of the microenvironment on drug resistance}

\subsubsection{Tumor vasculature and hypoxia}

Solid tumors often present tortuous, poorly differentiated and truncated vasculature, resulting in the delivery of suboptimal concentrations of cytotoxic drugs to certain niches (Minchinton AI and Tannock IF, 2006). This also accounts for the formation of a hypoxic environment that significantly influences cell metabolism and modulates gene expression, ultimately enhancing chemoresistance and maintenance of CSC (Rohwer $\mathrm{N}$ et al., 2011); discussed in detail in the following sections) (Figure 1). Furthermore, hypoxia modulates the expression of genes linked to EMT - (addressed in detail in subsequent sections) and drug resistance phenotypes (Adamaki M et al., 2012; Jiang J et al., 2011; Polyak K and Weinberg RA, 2009; Ruan K et al., 2009; Shannon AM et al., 2003).

The primary transcription factor mediating the response to hypoxic challenge is hypoxia-inducible factor-1 (HIF-1) (Semenza GL, 2001). HIF-1 consists of a constitutively expressed subunit HIF-1 $\beta$ and a tightly oxygen-regulated subunit HIF-1 $\alpha$ (or its paralogs HIF-2 $\alpha$ and HIF-3 $\alpha$ ) (Brocato $\mathrm{J}$ et al., 2014). Under normoxia conditions, the HIF-1 $\alpha$ protein is constitutively expressed but rapidly marked for proteosomal degradation, resulting in a very short cytoplasmic half-life (5-8 $\mathrm{min})$. Under hypoxic conditions, HIF-1 $\alpha$ is translocated to the nucleus where it binds to the co-activators HIF-1 $\beta$ and p300/CBP (Semenza GL, 2001), inducing an array of responses such as overexpression of angiogenic genes (i.e. VEGF, PDGF-BB and NOS) and growth factors (i.e. IGF-II) (Brocato J et al., 2014; Denko NC et al., 2003; Harris AL, 2002), decreases mitotic and metabolic rates and adapts energy requirements to the hypoxic challenge (Hockel M et al., 2001; Shannon AM et al., 2003). In particular, HIF$1 \alpha$ contributes to the dramatic shift of intracellular glucose metabolism from aerobic cellular respiration to anaerobic glycolysis through the transactivation of genes 
encoding glucose transporters (i.e. GLUT-1) and several rate-limiting enzymes of glycolysis (Jose C et al., 2011; Mucaj V et al., 2012). It also suppresses the tricarboxylic cycle (TCA) via the PDK1 gene, encoding pyruvate dehydrogenase kinase 1, which inactivates pyruvate dehydrogenase, resulting in fueling the TCA cycle with acetyl-CoA (Shirato K et al., 2011). Moreover, HIF-1 $\alpha$ has been shown to regulate the expression of cytochrome $\mathrm{C}$ oxidase (COX) allowing cancer cells to optimize the efficiency of respiration at different oxygen levels (Mucaj V et al., 2012). Ultimately, HIF-1 $\alpha$ contributes to cellular adaptation to hypoxic stress which can culminate in mitochondrial autophagy (Zhang $\mathrm{H}$ et al., 2008). By modulating mitochondria activity, HIF-1 $\alpha$ influences cell death mechanisms mainly by interfering with apoptotic and necrotic signaling (Greijer AE, Van der Wall E, 2004). Furthermore, HIF-1 $\alpha$ has also been shown to act as apoptosis suppressor in cancer cells through the regulation of antiapoptotic target genes and additional molecular mechanisms that still remain largely elusive (Adamaki M et al., 2012; Harris AL, 2002). For instance, hypoxic regulation of p53 has been proposed to be HIF-dependent; however, controversy remains over this topic. Nevertheless, most reports point to the fact that hypoxia acts as a positive selective pressure for the positive selection of p53 mutant cells and hence inducing diminished apoptotic potential (Ruan K et al., 2009), thereby compromising the response to chemotherapy (Gogna $\mathrm{R}$ et al., 2012; Weisz L et al., 2007). HIF-1 $\alpha$ also acts as a regulator of drug efflux through the activation of the MDRl gene encoding the multidrug resistance efflux transporter P-glycoprotein (P-gp; ABCB1) (Comerford KM et al., 2002; Rohwer $\mathrm{N}$ et al., 2011; Shannon AM et al., 2003). P-gp belongs to the ATP-binding cassette $(\mathrm{ABC})$ superfamily of transporters, however it does not recognize cisplatin as a transport substrate (Lockhart AC et al., 2003; Rohwer $\mathrm{N}$ et al., 2011), but is capable of markedly decreasing the intracellular concentration of a wide range of structurally and functionally distinct hydrophobic chemotherapeutic agents (Lockhart AC et al., 2003; Shapira A et al., 2011).

Under hypoxic conditions an association between high levels of HIF-1 $\alpha$ and cisplatin resistance has been widely reported for several representative tumor cell lines, including ovarian cancer (Su W et al., 2011), NSCLC (Fischer C et al., 2015), hepatocellular carcinoma and hepatic progenitor cell lines (Jiao M and Nan K, 2012). Supporting a role for HIF-1 $\alpha$ in chemoresistance, elevated levels of this key transcription factor have been observed in tumors of different tissue origin and linked to 
more resilient tumor cells, poor prognosis and resistance to radiotherapy and chemotherapy (Huang LA et al., 2007; Shannon AM et al., 2003; Wilson WR and Hay MP, 2011). Nevertheless, it should be noticed that, despite the pivotal role of HIF-1 $\alpha$, other independent mechanisms have been found to mediate hypoxia-related chemoresistance (Adamaki M et al., 2012; Scholten DJ et al., 2014). More detailed insights about the role of HIF in chemoresistance may be found in previous reviews by Rowner and Cramer (Rohwer N et al., 2011) and Raguz and Yagüe (Raguz S and Yague E, 2008).

\subsubsection{The tumor stroma}

The tumor stroma, mainly formed by the basement membrane, extracellular matrix, cancer-associated fibroblasts (CAFs), immune cells, and vasculature, is a complex structure whose interactions markedly affect tumor growth, invasion, and metastasis during the course of disease (Bremnes RM et al., 2011; Pietras K et al., 2010) (Figure 1). Over the recent years, the crosstalk between cancer cells and the tumor stroma has been progressively unveiled (see review Bremnes RM et al., 2011; Tripathi $\mathrm{M}$ et al., 2012). However, the dynamics of cancer cell death in response to cisplatin and the tumor microenvironment has yet to be fully characterized. Noteworthy, it has been shown that the presence of stroma in 574 breast cancer specimens from patients who underwent surgery combined or not with adjuvant radiotherapy, adjuvant chemotherapy or adjuvant endocrine therapy, was an independent prognostic factor for relapse-free period, particularly in the triple-negative subpopulation (de Kruijf EM, 2011). However, extracellular matrix components mediating resistance to chemotherapy are still poorly understood. Several in vitro studies have demonstrated that the extracellular matrix not only constitutes a physical barrier to drug dissemination (Choi I et al., 2013), but may also exert a protective effect against apoptosis induced by various anticancer drugs (Chen Y et al., 2010; Kouniavsky G et al., 2002; Sethi T et al., 1999). Miyamoto H and colleagues have further found that the grade of differentiation of pancreatic tumor cells affects the interaction with different ECM macromolecules (fibronectin, collagen I, and collagen IV) as well as the matrix-driven sensitivity to chemotherapeutic drugs, including cisplatin (Miyamoto $\mathrm{H}$ et al., 2004). The presence of fibronectin, type IV collagen, and laminin have also been linked to cisplatin-resistance and local recurrence 
of uveal melanomas (Bérubé M et al., 2005). The authors observed that apoptosis was less frequent after cisplatin administration in the presence of ECM when compared with cells cultured on a non-permissive matrix (Bérubé M et al., 2005). Several studies also found that the overexpression of ECM-associated genes correlates with increased cisplatin resistance (Januchowski R et al., 2014; Sherman-Baust CA et al., 2011; Sherman-Baust CA et al., 2003). In this respect, the gene expression profile of a subpopulation of the human ovarian carcinoma cell line A2780 displaying cisplatin resistance revealed a significant upregulation of the COL6A3 gene, encoding for collagen VI (Varma RR et al., 2005). These findings suggest that chemoresistance may modulate ECM composition through altered regulation of gene expression in cancer cells. Moreover, cisplatin-sensitive cells cultured in the presence of collagen VI showed enhanced resistance in vitro and immunohistochemistry studies revealed an association between collagen VI overexpression, tumor grade and resistance to chemotherapy (Sherman-Baust CA et al., 2003). Furthermore, ovarian tumors with pronounced stromal/mesenchymal gene signatures exhibited the worst outcome when compared to groups with non-stroma-associated gene signatures (Verhaak RGW et al., 2012). In addition, ECM gene signatures were associated with chemotherapy resistance (Mintz MB et al., 2005). Altogether, these findings suggest that tumor cells may remodel their microenvironment in order to increase survival to chemotherapeutic challenges (Sherman-Baust CA, et al., 2003). Recent studies point towards the pivotal role of $\beta 1$ integrins in ECM-cancer cells interactions and chemoresistance (Aoudjit F and Vuori K, 2012). According to Hodkinson PS et al., $\beta 1$-integrin-mediated PI3K activation prevents caspase-3 activation, thereby protecting small cell lung cancer cell lines against chemotherapy-induced cell cycle arrest and apoptosis (Hodkinson PS et al., 2007). A more recent report on oral carcinoma cell lines has shown that adhesions within the carcinoma matrix create an environment in which exposure to cisplatin induces proliferation through the function of $\beta 1$-integrin, talin and FAK pathways that regulate nuclear activity of NF-kB (Eberle KE et al., 2011). Based on these observations, it has been suggested that the inhibition of ECM-integrin interactions in combination with chemotherapy could have positive therapeutic implications (Mahadevan D and Von Hoff DD, 2007). Impaired binding of hyaluronan to transmembrane receptor CD44 has also been shown to influence multiple cell signaling pathways that stimulate tumor cell proliferation, migration, and matrix metalloproteinase secretion, and to promote CSC properties as well as cisplatin resistance (Bourguignon LY et al., 2013; Ohashi R et al., 
2007; Torre C et al., 2010). Several metalloproteinases that are responsible for the proteolysis of ECM components during biological processes such as carcinogenesis, differentiation, apoptosis, migration and invasion, tumor angiogenesis and immune surveillance may also contribute to modulate response to treatment (Blons $\mathrm{H}$ et al., 2004; Ertan E et al., 2011; Mahadevan D and Von Hoff DD, 2007). The balance between matrix metalloproteinases (MMP) and tissue inhibitors of metalloproteinases (TIMPs) is crucial for ECM stability (Nagase $\mathrm{H}$ et al., 2006) and acts in a coordinated manner to drive cancer progression and metastasis (Hara I, 2001; Rodriguez FO et al., 2012). Overexpression of TIMP-2, an inhibitor of MMP-2, in ovarian cancer stromal areas was found to be associated with better response to chemotherapy (Hałon A et al., 2012). Furthermore, in vitro studies of squamous cell carcinoma of the head and neck have shown significant correlations between resistance to cisplatin and the expression of TIMP-2, suggesting that TIMP-2-mediated chemoresistance is dependent on the physiological environment (Akervall J et al., 2004). However, studies using ovarian cancer cell lines failed to show any association between this MMP-2 inhibitor and cisplatin resistance (Hałoń A et al., 2012). Also, expression of MMP-7 and -13 was found to be associated with cisplatin resistance in head and neck cancer cell lines (Ansell A et al., 2009). Again, these observations suggest that the crosstalk between the microenvironment and cancer cells is essential in order to influence intrinsic cell characteristics and chemotherapy resistance. These findings imply that disruption of cell-matrix interactions may provide ways to block ECM-mediated upstream or downstream intracellular signaling cascades, which could result in the overcoming of cisplatin resistance. Taking into account the encouraging results from studies using matrix modulating agents in combination with chemotherapy (Hussain A et al., 2012; Kamaraj S et al., 2010; Pisano C et al., 2014), it is now important to fully clarify the role of ECM components in platinum resistance in order to design rational therapeutic approaches.

Stromal changes also include the development of carcinoma-associated fibroblasts (CAFs) that play a crucial role in disease (Tripathi M et al., 2012). In the recent years, the crosstalk between cancer cells and CAFs has been unveiled and comprehensively reviewed by several groups (Brennen WN et al., 2012; Liu R et al, 2012; Puré E, 2009). CAFs have been found to directly drive cancer development through multiple mechanisms, which include the promotion of angiogenesis, cellular 
proliferation, invasion and inhibition of apoptosis in cancer cells (Brennen WN et al., 2012; Hale MD et al., 2013). Numerous growth factors, cytokines, proteases, and extracellular matrix proteins, such as SDF-1, FGF2, VEGF, TGF- $\beta$, HGF, tenascin-c, LOX, and MMPs are among the key molecules mediating these processes. Growth factors and other proteins produced by activated fibroblasts not only act on cancer cells but also on other components of the stroma, including adipocytes, inflammatory and immune cells as well as in the remodeling of the ECM, hence creating intricate feedback loops mediated by paracrine and autocrine signaling that drives CAFs development, disease progression and dissemination (Brennen WN, 2012; Hale MD et al., 2013). Nevertheless, only limited data on the response of CAFs to chemotherapy and their potential impact on therapy outcome are available. Namely, Sonnenberg et al. addressed the influence of CAFs in lung and breast tumors as well as in primary cultures hence revealing that, similarly to cancer cells, the sensitivity of CAFs to cisplatin is highly variable and dependent on the cancer type and its microenvironment (Sonnenberg M et al., 2008). Moreover, studies have demonstrated that the presence of CAFs contributes to the decreased response to chemotherapy in prostate (Franco OE et al., 2012), breast (Rong G et al., 2013) and lung (Sonnenberg M et al., 2008) cancers. Furthermore, strategies targeting CAFs components have proven capable of improving the response to chemotherapy (Elenbaas B et al., 2001; Loeffler M et al., 2006), suggesting a role for these cells in treatment outcome. Also, a recent systematic review by Hale et al., has highlighted the fact that stroma-derived biomarkers, with emphasis on molecules produced by CAFs, are useful biomarkers to predict response to therapy (Hale MD et al., 2013). Several studies also support the notion that CSC, known for their intrinsic resistance to chemotherapy, also receive critical maintenance cues from supportive stromal elements, including CAFs (Hasegawa T et al., 2014; Li L et al., 2013; Liao CP et al., 2010). In this respect, the interplay between CSC and CAFs towards increased chemoresistance and CSC self-renewal and invasion, have been recently demonstrated for colorectal cancer; according to this study, chemotherapy induces the remodeling of the tumor microenvironment to support cellular hierarchy through secreted factors that include IL-17A (Lotti F et al., 2013).

Overall, there is a growing amount of evidence supporting the notion that stromal components promote chemoresistance; hence, the mechanisms underlying this stromal based chemoresistance should be critically evaluated hence paving the way 
towards the overcoming of this modality of drug resistance. Furthermore, the incorporation of therapeutics which target the tumor microenvironment may be a determinant for disrupting CSC maintenance mechanisms.

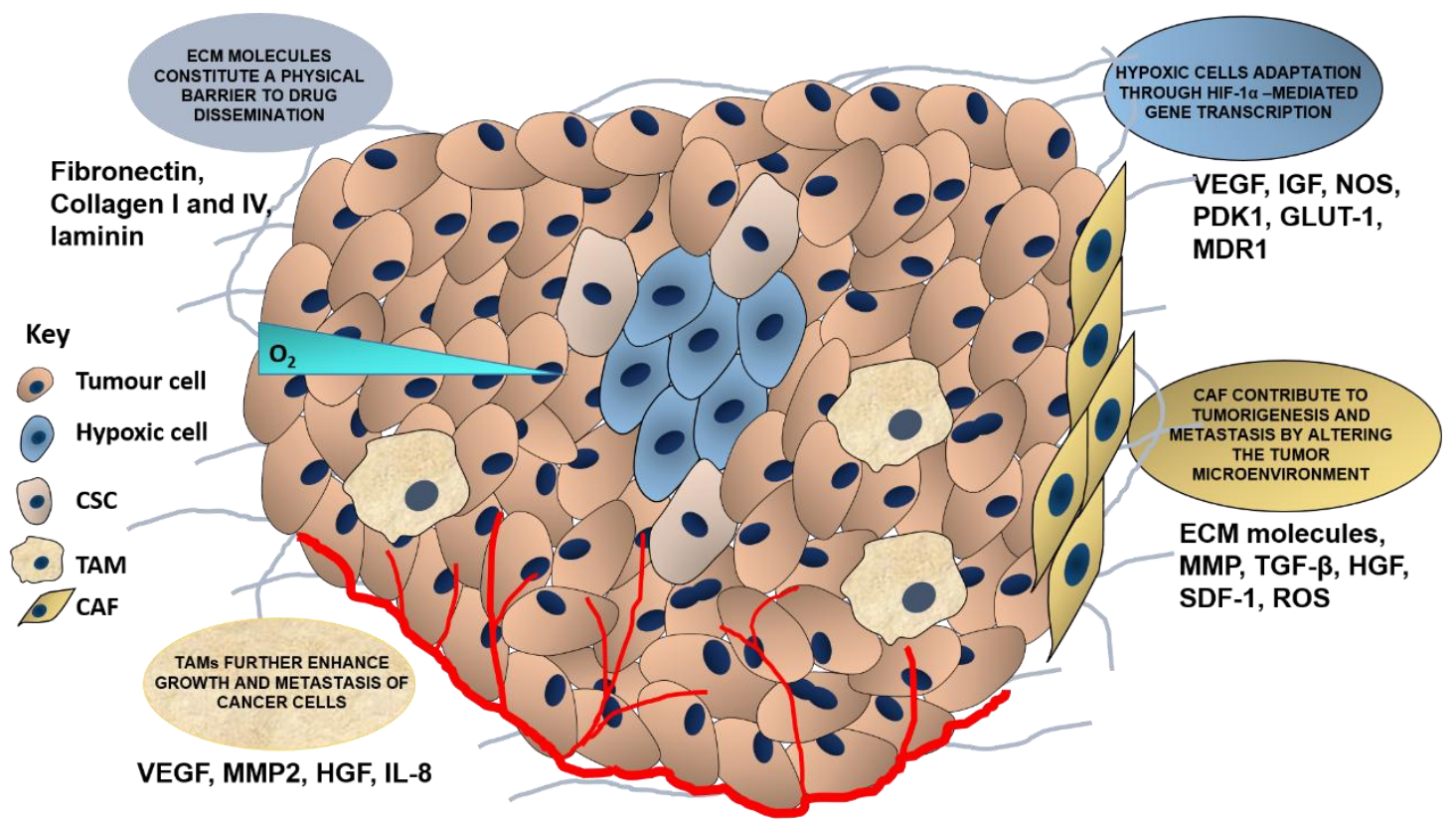

Figure 1. The microenvironment of solid tumors actively modulates cell metabolism, gene expression and chemotherapy response. Solid tumors frequently present inefficient vasculature, resulting in the delivery of suboptimal concentrations of cytotoxic drugs and highly hypoxic tumor cores. Stromal cells and the ECM strongly mediate tumor growth and stress response, and it constitutes a physical barrier for drug delivery.

\subsection{Alterations in intracellular drug concentrations}

Cisplatin-resistant tumor cells often present reduced intracellular platinum accumulation when compared to non-resistant cells following drug exposure. This may result either from reduced uptake or increased drug export (Stewart DJ, 2007).

\subsubsection{Cisplatin uptake}

Cisplatin uptake is mainly mediated by high affinity copper transporter protein 1 (hCtr1) and its down-regulation has been associated with resistance to platinum-based drugs in vitro (Holzer AK et al., 2004; Liang ZD et al., 2014; Liang ZD et al., 2012) and in vivo (Fu S et al., 2012) (Figure 2). An association between hCtr1 rs7851395 and 
rs12686377 polymorphisms and platinum resistance in NSCLC patients has also been described ( $\mathrm{Xu} \mathrm{X}$ et al., 2012). Nevertheless, more clinical studies are required to determine the prognostic value of hCtr1 and its genetic variants in the context of cisplatin treatment. The hCtr1 transporter protein is responsible by regulating intracellular copper homeostasis. In turn, the expression of hCTR1 is regulated at the transcriptional level by copper via the transcription factor Sp1 and at the posttranslational level by a mechanism involving copper-stimulated endocytosis and degradation of the transporter (Howell SB et al., 2010; Petris MJ et al., 2003). The exposure to copper-chelating agents has been proven to increase the expression of hCtr1 and sensitize tumor cells to platinum (Galluzzi L et al., 2012; Ishida S et al., 2010; Liang ZD et al., 2012). Furthermore, a pilot clinical trial has shown that administration of a copper-lowering agent can partially resensitize platinum-resistant high-grade epithelial ovarian cancer patients to platinum chemotherapy (Fu S et al., 2012). Altogether, these observations suggest a role for hCtr1 in cisplatin resistance and support larger studies to assess the efficacy of this approach in platinum-resistant cancers treatment. Other transporters such as Solute Carrier Family 22 Members 1 and 2 (Li Q and Shu Y, 2014; Yonezawa A et al., 2006) have also been implicated in cisplatin uptake; nevertheless, more studies are required to delineate their role in cisplatin resistance as well as their potential use as biomarkers for resistance to platinum cytotoxic agents.

\subsubsection{Cisplatin efflux}

The efflux of platinum-based drugs is believed to be mediated by Transporting P-type Adenosine Triphosphatases ATP7A and ATP7B (Drayton RM et al., 2012; Stewart DJ, 2007; Tadini-Buoninsegni F et al., 2014) (Figure 2). Unsurprisingly, the overexpression of these transmembrane carriers have been implicated in cisplatin resistance and poor patient survival in several cancers (Konkimalla VB et al., 2008; Tadini-Buoninsegni $\mathrm{F}$ et al., 2014; Yoshizawa K et al., 2007). Silencing ATP7A in cisplatin-resistant tumor cells restored cisplatin sensitivity to a certain extent and enhanced apoptosis, suggesting that ATP7A may also be a target to sensitize cancer cells to cisplatin ( $\mathrm{Li} \mathrm{ZH}$ et al., 2012). Resistance to cisplatin has also been associated with the overexpression of Multidrug resistance-associated proteins (MRP) 1, 2, 3 and 
5, members of the superfamily of ABC transporters (Borst P et al., 2000; Guminski AD et al., 2006; Konkimalla VB et al., 2008; Song Y et al., 2015) (Figure 2). In particular, MRP2 expression seems to determine the efficacy of cisplatin-based chemotherapy in patients with hepatocellular carcinoma (HCC) (Korita PV et al., 2010). Furthermore, a reduction in MRP2 expression using ribozymes has been shown to restore cisplatin sensitivity in cisplatin-resistant adrenocortical carcinoma and melanoma cell lines (Materna V et al., 2005), further suggesting a role for this molecule in cisplatin resistance. Nevertheless, it has been demonstrated that cisplatin is not a substrate for MRP transporters and that its ability to transport the drug across the cell membrane requires the formation of glutathione- or metallothioneins-cisplatin conjugates (discussed in detail in the following section) (Chen ZS et al., 1998; Fujiwara Y et al., 1990; Kelland L, 2007) (Figure 2).

\subsubsection{Detoxification by intracellular molecules}

Although purine nucleobases are the main therapeutic target for cisplatin, a vast majority of cisplatin molecules will react with other ligands before reaching the nucleus. In particular, cisplatin shows much higher affinity for thiols than for nitrogen groups, hence making intracellular cisplatin detoxification via these functional groups one of the main mechanisms of cisplatin scavenging (Dabrowiak JC et al., 2002). As such, resistance to cisplatin has been associated with the overexpression of metallothioneins, a class of low-molecular weight cysteine-rich proteins that promote intracellular homeostasis of physiological metals, providing protection against metal toxicity and oxidative stress (Knipp M, 2009) (Figure 2). This has been observed in different cancer models (Gansukh T et al., 2013; Peng B et al., 2012) as well as in bladder (Siu LL et al., 1998; Wülfing C et al., 2007), colorectal (Hishikawa Y et al., 2001), esophageal (Yamamoto M et al., 1999), and breast (Bay BH et al., 2006; Lai Y et al., 2011) carcinomas, among other neoplasia.

Glutathione (GSH), a thiol containing tripeptide (Glu-Cys-Gly), highly expressed in mammalian cells, also plays a key role in cisplatin scavenging (Rocha CR et al., 2014) (Figure 2). Glutathione-S-transferase 1 (GSTP1-1) conjugates the reduced form of glutathione (GSH) to xenobiotic substrates for the purpose of detoxification and catalyzes the formation of cisplatin-GSH conjugates (Peklak-Scott C et al., 2008; Sawers L et al., 2014). As such, increased expression of enzymes involved in GSH 
synthesis and GSH conjugation have been implicated in the generation of cisplatin resistance (Galluzzi L et al., 2012; Rocha CR et al., 2014). Also, elevated levels of glutamate/cysteine transport system (system Xc) were linked with higher intracellular levels of GSH and resistance to cisplatin (Okuno S et al., 2003). The efflux of intracellular glutathione S-cisplatin conjugates is an ATP-dependent process mediated by integral membrane glycoproteins belonging to the MRP family (Ishikawa T and AliOsman F, 1993; Keppler D, 1999). Furthermore, MRP transporters are overexpressed in cisplatin-resistant human cancer cells whose GSH levels are substantially enhanced (Chen HHW and Kuo MT, 2010; Ishikawa T et al., 1994), suggesting that GSH and MRP proteins work in synergy for detoxification purposes.

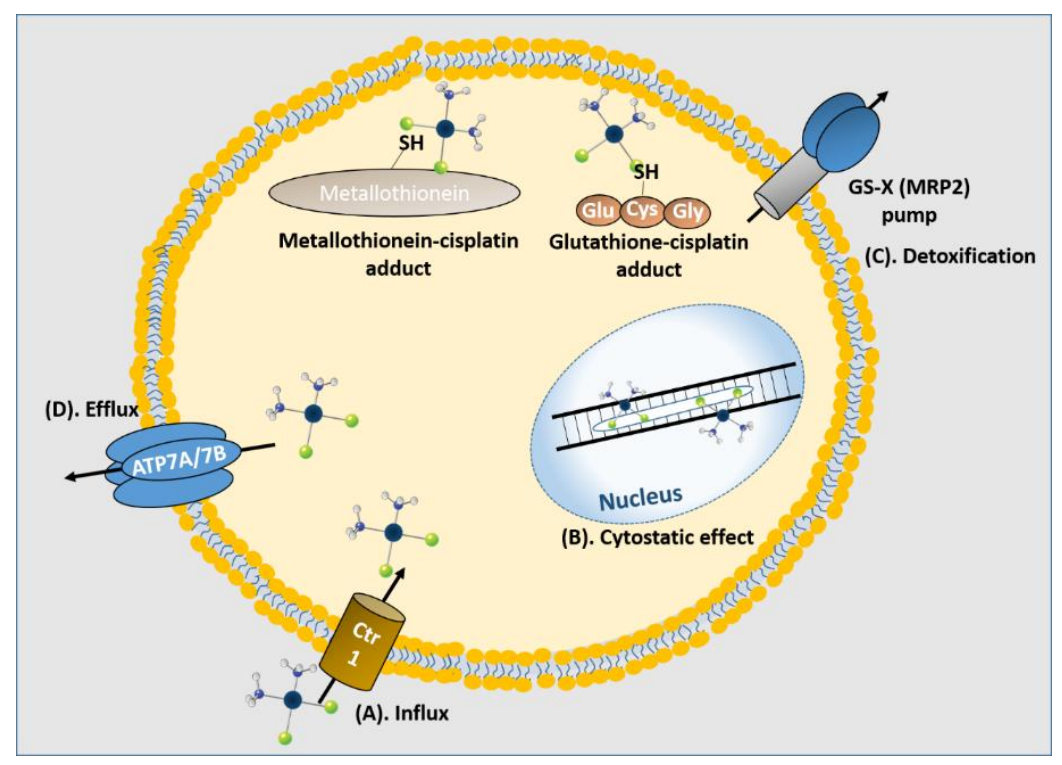

Figure 2. Intracellular cisplatin concentration depends on several detoxification mechanisms. (A). Cisplatin uptake is mainly mediated by high affinity copper transporter protein $1(\mathrm{Ctr} 1)$. Once inside the cell, cisplatin has a number of possible targets: DNA; RNA; sulfur-containing enzymes such as metallothionein and glutathione; as well as mitochondria. (B). The alkylating capability of cisplatin enables the formation of adducts with N7 atoms of DNA purine nucleobases, resulting in interand intra-strand DNA cross-links that provoke cell cycle arrest. (C). Glutathionecisplatin and metallothionein-cisplatin conjugates are excreted by MRPs, hence decreasing intracellular cisplatin accumulation. (D). The efflux of platinum-based drugs is mainly mediated by Transporting P-type Adenosine Triphosphatases ATP7A and ATP7B. 


\subsection{Alterations in DNA repair systems}

Several DNA repair pathways interact to maintain accurate DNA replication, genomic integrity and normal cell functioning. These include: i) nucleotide excision repair (NER); ii) base excision repair (BER); iii) homologous recombination repair (HR); iv) mismatch repair (MMR); v) non-homologous DNA end-joining repair (NHEJ); vi) $\mathrm{O}^{6}$ - alkylguanine DNA alkyl transferase (AGT) mediated repair. Increased efficiency of DNA repair systems is considered essential for the maintenance and longevity of stem cell phenotypes and plays a key role in cytotoxic drugs resistance (Martin LP et al., 2008). This review will discuss the most studied DNA repair pathways involved in platinum response, i.e., nucleotide excision repair (NER) and mismatch repair (MMR), and will briefly refer the role of BRCA in DNA repair (Figure $3)$.

Several reports describe associations between the alterations in the XPF-ERCC1 protein complex of the NER system and platinum-based treatment outcome (Kirschner $\mathrm{K}$ and Melton DW, 2010) (Figure 3). This complex is a structure-specific endonuclease involved in recombination, double strand break and inter-strand crosslink repair (Ahmad A et al., 2008). The impossibility to replace damaged nucleotide sequences promotes downstream activation of the mitochondrial BAX protein, inducing apoptosis (Pawlowski J and Kraft AS, 2000) (Figure 4). As such, XPF-ERCC1 overexpression has been found to promote resistance to platinum-based compounds in vitro (Arora $\mathrm{S}$ et al., 2010; Kirschner K and Melton DW, 2010; McNeil EM and Melton DW, 2012), most likely due to overefficient DNA repair. In agreement with these observations, retrospective studies involving patient's histological samples have highlighted an association between the overexpression of ERCC1, resistance to chemotherapy and poor outcome in squamous cell head and neck (Bauman JE et al., 2013) and bladder carcinomas (Sun JM et al., 2012). A recent clinical trial has also demonstrated that elevated expression of the ERCC1 gene is an independent prognostic factor for overall survival in first line treatment of advanced gastric cancer (Kwon HC et al., 2007). Furthermore, a phase II trial showed that single nucleotide polymorphisms of ERCC1 gene (118T/C and 8092C/A) could be used to determine the response of NSCLC patients to cisplatin (Mazzoni F et al., 2013). Another study has demonstrated that 8092C/A could be used as an independent predictive biomarker of better response in esophageal cancer patients treated with cisplatin-based regimens (Bradbury PA et al., 
2009). An enhanced expression of ERCC1 has also been observed in esophageal (Zhao Y, Bao Q, Schwarz B, Zhao L, Mysliwietz J, Ellwart J, Renner A, Hirner H, Niess H, Camaj P, Angele M, Gros S, Izbicki J, Jauch KW, Nelson PJ, 2014) and ovarian (Abubaker K et al., 2013) platinum-resistant cancer-stem cell sub-populations.

Cisplatin resistance has also been associated with somatic mutations in Mismatch Repair system-associated proteins (MMR), namely in MSH2 and MSH3 proteins (Clodfelter JE et al., 2005; Karran P et al., 2003; Park JM et al., 2013) (Figure 3). MSH2, together with MSH3, form the MutS $\beta$ heteroduplex which interacts with interstrand crosslinks induced by drugs such as cisplatin (Muniandy PA et al., 2010). Recognition of mismatched base pairs by MMR proteins may directly activate apoptotic pathways, thereby leading to cell death. As such, cisplatin-resistance is often accompanied by loss of expression of MMR proteins (Topping RP et al., 2009). Takahashi et al., has further demonstrated that MSH3 deficiency contributes to the cytotoxicity of platinum drugs through deficient repair of double strand breaks in the established colorectal cancer cell line HCT116 (Takahashi M et al., 2011). Moreover, Velasco A et al., demonstrated that decreased MMR expression in testicular tumors is associated with a shorter time to recurrence and death despite chemotherapy (Velasco A et al., 2008).

Likewise, disruption of the homologous recombination (HR) system, responsible for DNA double-strand break repair during the S-phase of the cell cycle, has been shown to modulate response to cisplatin (Wang QE et al., 2011; Wiedemeyer WR et al., 2014) (Figure 3). In particular, breast cancer susceptibility proteins 1 and 2 (BRCA1/2) play an important role in DNA repair by interacting with components of DNA repair systems and through gene expression regulation of homologous recombination, nonhomologous end joining, and nucleotide excision repair intermediates. As such, BRCA proteins affect transcriptional regulation, cell cycle control, apoptosis, and ubiquitination (Deng CX and Wang RH, 2003; Mullan PB et al., 2006; Wu W et al., 2008). Normally, cancer cells with BRCA1/2 deficiency present defective DNA repair by homologous recombination and are sensitive to interstrand DNA crosslinking agents, such as cisplatin. Therefore, these agents are natural choices for the treatment for BRCA1/2-deficient tumors and were shown to be clinically effective (Shah NP, 2008). In contrast, during tumor expansion or as a result of chemotherapy, genetic reversion of BRCA1 or BRCA2 mutations can occur mainly due to secondary mutations and 
restoration of function, leading to cisplatin resistance (Dhillon KK et al., 2011; Peng G and Lin SY, 2011). Loss of function mutations in genes encoding HR system proteins, BRCA1/2 were associated with increased response to cisplatin in breast (Turner NC and Tutt AN, 2012) and ovarian tumors (Kwa M et al., 2014). Also, overexpression of BRCA1 in cisplatin-resistant human breast and ovarian carcinoma cell lines (MCF-7 $\mathrm{CDDP} / \mathrm{R}$ and SKOV-3 $\mathrm{CDDP} / \mathrm{R}$, respectively), resulted in increased resistance to cisplatin. In turn, antisense inhibition of BRCAl expression enhanced cisplatin sensitivity associated with decreased DNA repair by NER and increased apoptosis in the ovarian carcinoma cell line (Husain A et al., 1998). Furthermore, BRCA1 mRNA expression levels were also inversely correlated with sensitivity to cisplatin in malignant pleural effusions of NSCLC patients and in ascites of gastric patients (Wang L et al., 2008). In addition, several retrospective clinical studies have demonstrated that low BRCA1 mRNA expression was associated with longer survival of breast, ovarian, small cell lung cancer and esophageal squamous cell carcinoma (James CR et al., 2007; Margeli M et al., 2010; Quinn JE et al., 2007) subjected to cisplatin-based therapeutic regimens, and could be therefore used as predictive and prognostic marker. Moreover, several studies, recently comprehensively reviewed by Buckley et al., suggest a role for BRCA1 in stem cell regulation through activation of the p63 and Notch pathways (Buckley NE et al., 2012).Collectively, these studies suggest that functional mutations in BRCA1 as well as reduced BRCA1 mRNA levels may predict a benefit from DNAdamage-based chemotherapy. Furthermore, they highlight a link between BRCA1, stem cell regulation and response to chemotherapy. More detailed information regarding the role of DNA repair systems in resistance to platinum-based treatment can be found in recent reviews by Martin LP et al., (Martin LP et al., 2008).

Some of the above described DNA repair-associated effectors were found overexpressed in CSC, when compared with differentiated tumor cells (Maugeri-Saccà $M$ et al., 2012). For instance, a significant increase in gene copy number of BRCAl and $R A D 51$ has been observed in prostatic CSCs compared with the adherent population isolated from the primary site (Maugeri-Saccà M et al., 2012). Therefore, it has been hypothesized that CSC are endowed with proficient DNA repair mechanisms which allow them to resist conventional chemotherapy and act as tumor initiators (Mathews LA et al., 2011), urging CSC-targeted therapeutics aimed at the elimination of these residual tumorigenic cell sub-populations. 


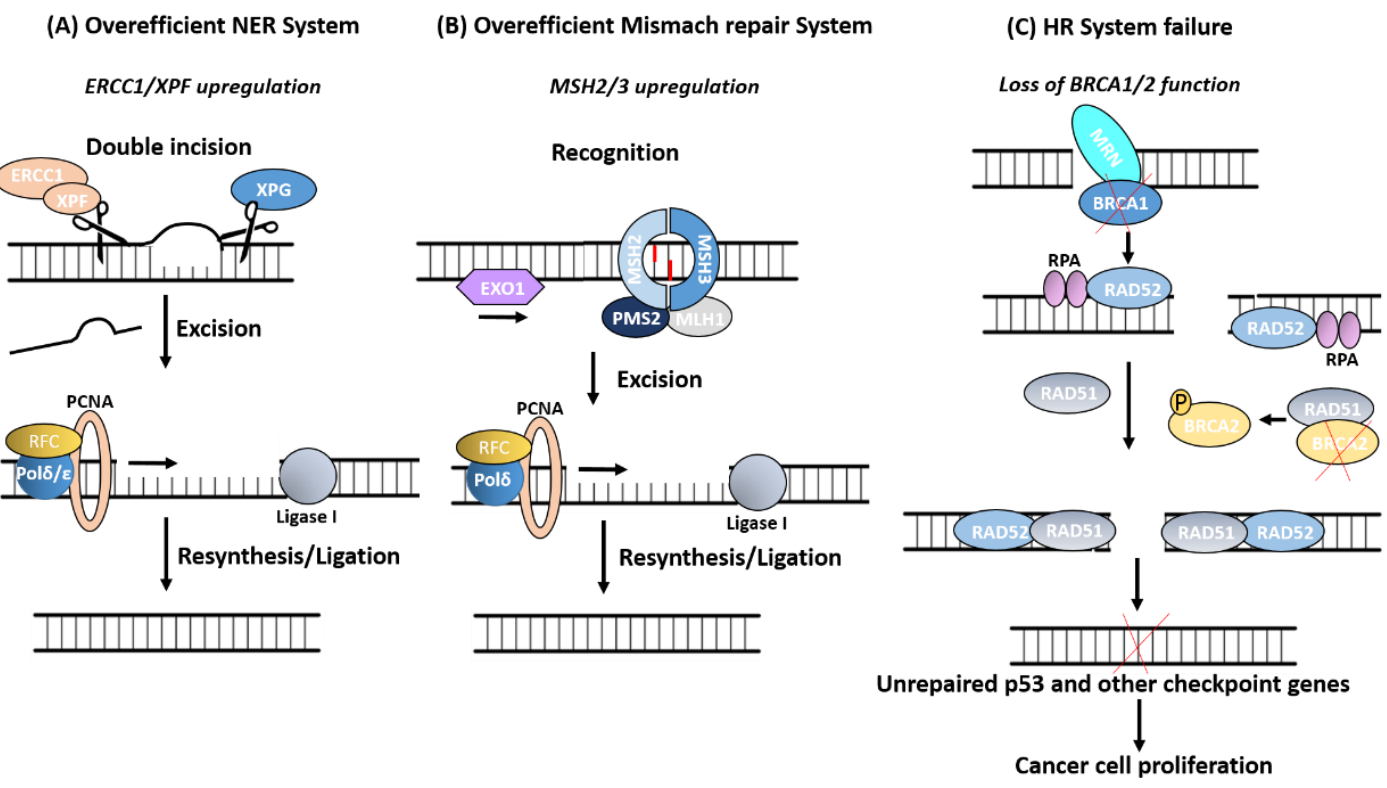

Figure 3. Alterations of DNA repair mechanisms mediate platinum-resistance. (A) Upregulation of XPF-ERCC1 complex results in resistance to platinum-based regimens by promoting NER overefficiency. Both XPG and XPF-ERCC1 are specific for junctions between single- and double-stranded DNA. XPG, which is closely related to the FEN-1 nuclease that participates in base excision repair (BER), cuts on the 3' side of such a junction, while ERCC1/XPF (a heterodimeric protein complex) cuts on the 5' side. The cut made by XPG is 2-8 nucleotides from the lesion, and the cut made by ERCC1/XPF is 15-24 nucleotides away. Next, the replicative gap-repair proteins, RFC, PCNA, and DNA polymerase delta or epsilon, bind to the 3 '-OH generated by the ERCC1-XPF cut, and they carry out new DNA synthesis that fills the gap. The final nick is sealed by DNA ligase I. (B) Overexpression of MSH DNA-repair proteins leads to cisplatin chemoresistance. The DNA mismatch-repair system includes MSH2, MSH3/6, MLH1 and PMS2. MSH2-MSH3 heterodimers bind to single base-pair mismatches; then heterodimers such as MLH1-MLH3, and PMS2, as well as EXO1, are recruited to this complex. Then, the replicative gap-repair proteins and Ligase I fill and seal the gap, as previously described (Clodfelter JE et al., 2005; Takahashi M et al., 2011). (C) BRCA1/2 deficiency is associated with platinum resistance. After DNA damage is introduced, the MRN complex processes the ends of the DSBs. BRCA1 is phosphorylated by ATM and CHK2 (not shown) and regulates the MRN complex. RPA then associates with the $3^{\prime}$ ssDNA overhangs and becomes phosphorylated. Rad52 binds 
RPA and displaces it to allow for Rad51 binding. BRCA2 binds to Rad51 until BRCA2 becomes phosphorylated, releasing Rad51 and allowing it to localize to the DSB with Rad52. Rad51 then forms a nucleoprotein filament that invades a homologous sequence and activates strand exchange to generate a crossover between the juxtaposed DNA (not shown). BRCA. BReast CAncer genes; EXO1. Exonuclease 1; MLH. MutL homologues; MRN complex. This protein complex consists of Mre11, Rad50 andNbs1

proteins; MSH. MutS protein homolog; PCNA. Proliferating-cell nuclear antigen; PMS2. Post-meiotic segregation 2; Pol $\delta / \varepsilon$. DNA polymerase $\delta / \varepsilon ;$ RAD. Checkpoint protein; RFC. Replication factor C; RPA. Replication protein A.

\subsection{Alterations in apoptosis-regulatory pathways}

The cytotoxic effect of cisplatin is primarily mediated by the activation of a multibranched pro-apoptotic signaling cascade in response to the impossibility to repair DNA damage. Details on these mechanisms have been extensively and comprehensively reviewed by several groups (Basu A and Krishnamurthy S, 2010; Siddik ZH, 2003). As such, the response to cisplatin is significantly dependent on functional apoptotic pathways. Furthermore, genetic and epigenetic alterations in genes encoding key mediators of these processes have been long recognized to be associated with drug resistance (Dasari S et al., 2014; Galluzzi L et al., 2012; Shen D et al., 2012). These events may either result in enhanced survival stimuli, diminished death stimuli or diminished sensibility to death signals. Perhaps the most common and well documented apoptosis-related deregulation associated with cisplatin resistance stems from the inactivation of the tumor suppressor protein p53 (Galluzzi L et al., 2012; Siddik ZH, 2003) (Figure 4). Furthermore, several studies demonstrated that cancer patients harboring wild-type TP53 have a higher probability to benefit from cisplatin-based chemotherapy than patients with TP53 mutations (Gadducci A et al., 2002; Liang X et al., 2011). Consistently, mutations occur infrequently $(<3 \%)$ in germ cell tumors like testicular cancer, even though p53 protein is overexpressed in the vast majority of tumor samples (Guillou L et al., 1996), reinforcing the key role of p53 as a mediator of chemotherapy response. Other p53-related nuclear transcription factors including p63 and $\mathrm{p} 73$, are also part of a network that together with p53, contribute to regulation of apoptosis and tumorigenesis (Flores ER et al., 2005; Flores ER et al., 2002) as well as to 
chemotherapy-induced DNA damage response (Leong CO et al., 2007; Müller M et al., 2006; Rocco JW et al., 2006; Yuan M et al., 2010). Multiple promoters and alternative splicing events result in the expression of several isoforms of these transcription factors, which include full-length isoforms with transactivation domains (TA) homologous to that of full-length p53, and amino-terminally truncated (DeltaN) isoforms, which lack the TA domains. The TA isoforms of p63 and p73 are able to activate downstream target genes and promote apoptosis. Conversely, the DeltaN isoforms may act as dominant inhibitors of the full-length forms of p53, p63 and p73, hence impairing the activation of target genes and inducing apoptosis upon chemotherapy challenge (Courtois S et al., 2002; Marcel V et al., 2012; Takahashi R et al., 2014) (Figure 4). Several studies have further demonstrated that interfering with the expression or function of DeltaNp63 and/or DeltaNp73 and/or mutant p53 in tumor cells contributes to the improvement of tumor response to chemotherapy (Müller M et al., 2005; Müller M et al., 2006).

Alterations in other proteins mediating apoptosis triggered either by DNA damage or oxidative stress, via the mitochondrial pathway or by the extrinsic route, may also influence sensitivity to cisplatin (Henkels KM and Turchi JJ, 1999; Tanida S, Mizoshita T et al., 2012). Several death receptors, cytoplasmic adaptors, pro- and antiapoptotic members of the Bcl-2 protein family, caspases, calpains, and mitochondrial intermembrane proteins are among the factors shown to modulate the response to cisplatin in vitro (Henkels KM and Turchi JJ, 1999; Park MS et al., 2002; van Oosterwijk JG et al., 2012). Moreover, some have been suggested to modulate clinical response (Aggarwal H et al., 2007; Muris JJ et al., 2005). Namely, high endogenous expression of anti-apoptotic members of the Bcl-2 family, such as Bcl-2 and Bcl- $\mathrm{X}_{\mathrm{L}}$, were associated with increased cisplatin resistance (Michaud WA et al., 2009). Likewise, loss of Bax and Bak causes complete resistance to cisplatin (Qian W et al., 2014) (Figure 4). Moreover, studies involving the combination of cisplatin with the Bcl2-inhibitor ABT-737 have shown an improvement in the response to cisplatin, through a synergistic effect mediated by Noxa, to promote cell death and loss of clonogenic survival (Li R et al., 2009). Overexpression of survivin, a caspase-inhibitory protein often upregulated in response to cisplatin by phosphoinositide-3-kinase (PI3K)/AKT1dependent mechanisms (Belyanskaya LL et al., 2005), has also been associated with lack of response to cisplatin and unfavorable outcome in gastric (Sun XP et al., 2014), 
esophageal (Kato $\mathrm{J}$ et al., 2001), ovarian (Jiang L et al., 2013) and NSCLC tumors (Wang HQ et al., 2014). Moreover, the administration of survivin inhibitors (for example, YM155, LY2181308) have also been found to improve the outcome of several malignancies (Church DN et al., 2012).

Several of the abovementioned mechanisms have been found to endow CSC with the capability to evade death signals, hence compromising chemosensitivity (Fulda S, 2013; Signore M et al., 2013). More detailed insights on the mechanisms regulating apoptosis in CSC can be found in recent reviews (He YC et al., 2014; Medina V et al., 2009). As recently revised by Signore et al., several strategies exploiting signaling pathways that govern self-renewal and survival of CSC are currently approved or are being tested in clinical trials (Signore M et al., 2013). Strategies to sensitize CSC to chemotherapy include the stimulation of death receptors using Apo2L/TRAIL inducers (Plasilova M et al., 2002; Ravi R et al., 2004). By promoting the activation of the apoptotic extrinsic pathway, this strategy has the potential to overcome drug resistance in many tumors harboring p53-inactivating mutations (Ashkenazi A et al., 2008). Several antibodies and small molecules targeting the mitochondria-associated apoptosis machinery have also been developed including the Bcl-2 inhibitor ABT-727 that was able to sensitize glioma CSC to TRAIL treatment both in vitro and in vivo (Tagscherer $\mathrm{KE}$ et al., 2008). The inhibition of EGF-R/Akt pro-survival signaling is also among the most explored strategies to indirectly induce apoptosis of CSC (Gallia GL et al., 2009; Signore $M$ et al., 2013). Despite the significant success presented by these strategies, it is now consensual that sub-populations of CSC with distinct genetic features may coexist within the same tumor (He YC et al., 2014; Wang W et al., 2014) and significant molecular variations were also observed between CSC isolated from tumors of the same organ and different organs (Frank NY et al., 2010). This phenotypic heterogeneity accounts for significant variations in response to targeted strategies and highlights the need for a careful evaluation of the signal transduction pathways that drive each subpopulation of CSC to evade apoptosis, towards personalized cancer treatments. Furthermore, despite the encouraging reports with patient-derived xenografts capable of recapitulating CSC expression and tumor heterogeneity in immune deficient animals (Dobbin ZC et al., 2014; Whittle JR et al., 2015; Williams SA et al., 2013), more efforts should be devoted to the development of reliable clinical models able to support the development of new anti-cancer strategies. 


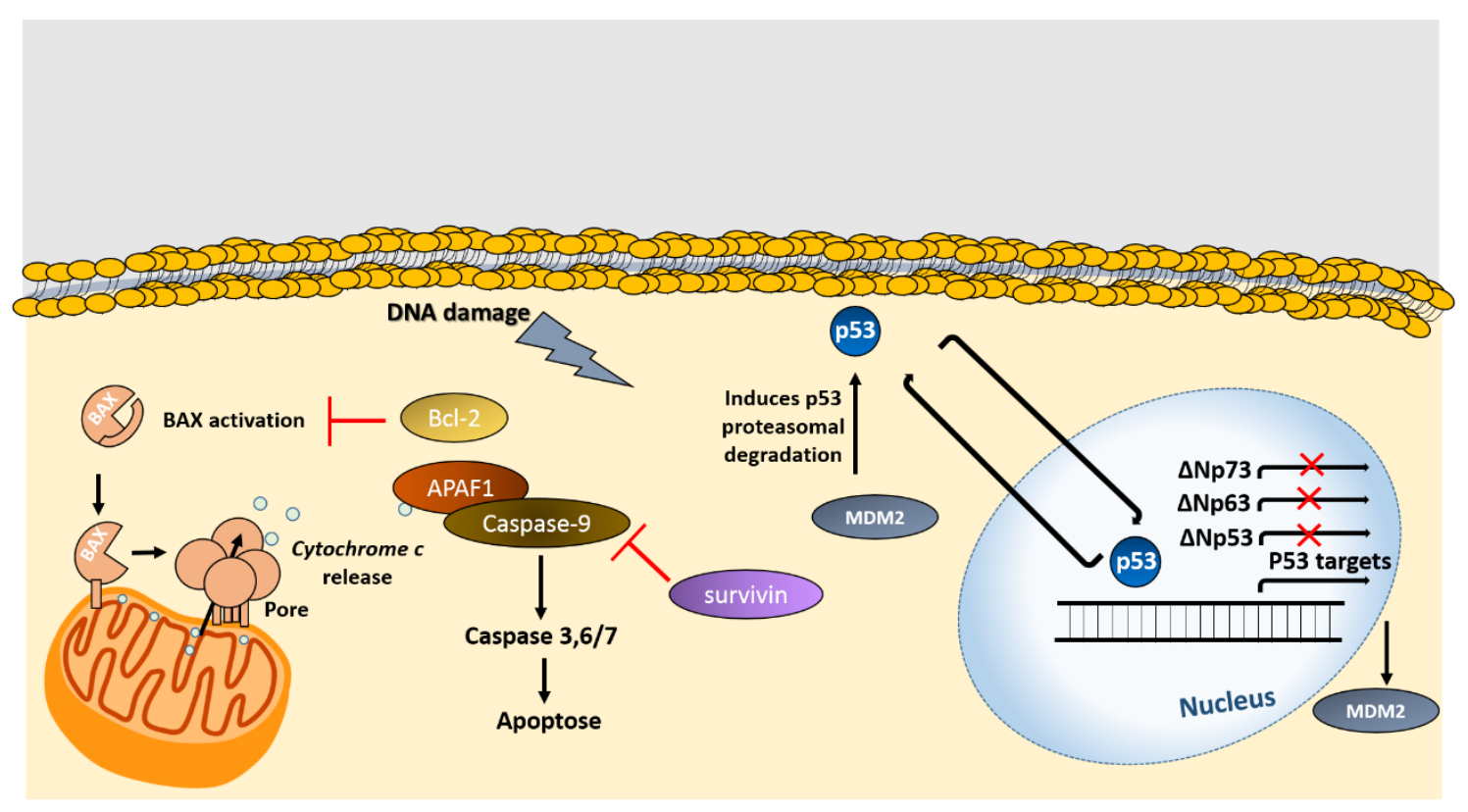

Figure 4 Anti-apoptotic members of the Bcl-2 family such as Bcl-2, Bcl-XL, and Bcl-w regulate the susceptibility to apoptosis through the intrinsic pathway. (A) BAX (B-cell lymphoma 2 (BCL-2)-associated protein $\mathrm{X}$ ) is sequestered in an inactive state at the outer mitochondrial membrane by binding to members of the anti-apoptotic Bcl-2 family. Upon various stimuli, anti-apoptotic BCL-2 family members are displaced from BAX and lead to the release of cytochrome $c$ from mitochondria. After being released, cytochrome $c$ binds the apoptotic peptidase activating factor 1 (APAF1), which forms a complex with caspase-9. The complex activates additional caspases leading to cellular death. (B) DeltaN isoforms of p53, p63 and p73 may act as dominant inhibitors of the full-length forms, hence impairing the activation of target genes. MDM2 is a major cellular antagonist of p53 and interferes with the tumor suppressor function of $\mathrm{p} 53$.

3. Protein glycosylation in cancer: Implications for chemotherapy response and CSC targeting

\subsection{Protein Glycosylation: Structural diversity in cancer}

Glycosylation is the most frequent, complex and plastic posttranslational modification of membrane-bound and secreted proteins and results from a coordinated action of nucleotide sugar transporters and biosynthesis pathways, glycosyltransferases 
and glycosidases in the endoplasmic reticulum (ER) and the Golgi apparatus (GA) (Pinho SS and Reis CA, 2015; Spiro RG, 2002). Glycans play a key role in protein folding, trafficking, stability, activity and act as mediators of cell-cell adhesion, cell differentiation, migration, modulation of cell signaling pathways, immune recognition and host-pathogen interactions (Haltiwanger RS et al., 2010; Ohtsubo K and Marth JD, 2006; Pinho SS and Reis CA, 2015; Shental-Bechor D et al., 2009). Two main classes of glycans can be found at the cell-surface: i) $O$-glycans, initiated in the Golgi apparatus by the initial attachment of GalNAc moieties to the hydroxyl groups of Ser or Thr residues of a given polypeptide chain (forming the Tn antigen GalNAc $\alpha$-Ser/Thr, the simplest form of $O$-glycosylation); ii) $\mathrm{N}$-glycans, whose biosynthesis initiates in the ER by the addition of an oligosaccharide chain to an Asn residue within consensus peptide sequences of Asn-X-Ser/Thr (X denotes any amino acid except proline). Less abundant forms of protein glycosylation include $O$-Fucosylation, $O$-Glucosylation and $C$ mannosylation of Thr residues (Pinho SS and Reis CA, 2015; Spiro RG, 2002). Protein glycan chains are often branched or elongated and may present sialic acids in blood group related antigens or $\mathrm{ABO}(\mathrm{H})$ blood group determinants as terminal structures (Dall'Olio F et al., 2012). Other modifications may include phosphorylation, $O$ acetylation of sialic acid and $O$-sulfation of galactose and $N$-acetylglucosamine residues, thereby increasing the structural complexity of the glycophenotype (Muthana SM et al., 2012). Furthermore, protein glycosylation patterns do not obey a predefined template (Lazar IM et al., 2011), as it is regulated at the tissue level, and promptly responds to physiological changes and cues (Ohtsubo K and Marth JD, 2006; Palorini R et al., 2013; Shirato K et al., 2011b; Testa $\mathrm{R}$ et al., 2015). In fact, variations in glucose and oxygen levels, among other microenviromental stimuli and signaling molecules, have been shown to influence the transcription and activity of glycosyltransferases and glycosidases, the trafficking of these enzymes to the ER and the Golgi apparatus and the availability of sugar donors (Carvalho AS et al., 2010; Dall'Olio F et al., 2012; Gill DJ et al., 2013; Pinho SS and Reis CA, 2015; Shirato K et al., 2011b). Recent studies have challenged the classical view of protein glycosylation as an intracellular event by demonstrating that glycans may experience further structural remodeling by extracellular enzymes (Lee MM et al., 2014; Nasirikenari M et al., 2014). This makes the glycome a highly dynamic molecular entity that mirrors a particular biological milieu and the glycomic/glycoproteomic characterization, a challenging analytical enterprise. Detailed insights on the structure of these glycans and their biosynthesis are 
available in several reviews and textbooks on the subject (Brockhausen I et al., 2009; Stanley P et al., 2009) and will not, therefore, be discussed in detail.

Malignant transformation is often accompanied by the expression of glycosylated structures that promote tumor growth, cell survival, cell-to-cell detachment, migration, immune evasion and metastasis (Figure 5, Christiansen MN et al., 2014; Dall'Olio F et al., 2014, 2012; Gomes C et al., 2013; Pinho S et al., 2007; Radhakrishnan P et al., 2014). In some cases, malignant tissues recapitulate the glycosylated antigens expressed during fetal life (Feizi T, 1985; Hakomori S, 1989; Varki A et al., 2009). Perhaps the most studied cancer-associated glycans include variants resulting from a premature stop in protein $O$-glycosylation, namely the $\mathrm{Tn}$ antigen (the simplest $O$-glycan), its sialylated counterpart sialyl-Tn (sTn; Neu5Aca26GalNAc $\alpha-O-S e r / T h r)$ and the $\mathrm{T}$ or core 1 antigen that results from the addition of a Gal residue to the Tn antigen (Galß1-3GalNAc-Ser/Thr) (Cazet A et al., 2010; Ju T, Lanneau GS et al., 2008; Julien S et al., 2012; Marcos NT et al., 2004). These antigens have been classically termed simple mucin-type $O$-glycans reflecting the abundance of $O$-glycosylation sites in mucins and stem from the incapability of the cellular glycosylation machinery to produce more elongated glycans. Recently, a precision mapping of the human O-GalNAc glycoproteome has revealed over 6000 glycosites in more than $600 \mathrm{O}$-glycoproteins, the majority of which were found at the cell surface (Campos D et al., 2015; Schjoldager KT and Clausen H, 2012; Steentoft C et al., 2013; Steentoft $\mathrm{C}$ et al., 2011), thereby greatly expanding the view of the $O$-glycoproteome and its functional role. Of note, several intracellular proteins, including cytoplasmic, mitochondrial and nuclear proteins, have also been found expressing this type of posttranslational modification (Steentoft $\mathrm{C}$ et al., 2013). Despite the need for further analytical validation, these observations may suggest a currently neglected role for $O$ GalNAc glycosylation in intracellular physiological and pathological events. Similar subsequent studies have contributed to the notion that cells of different origins express a minor and unique $O$-glycoproteome that should be carefully explored when envisaging highly specific cancer biomarkers (Campos D et al., 2015; Campos D et al., 2015)

While hindered by extended glycosylation in healthy and benign tissues, simple mucin-type $O$-GalNAc glycans are uncovered in the majority of human carcinomas, particularly in advanced stages of the disease (Figure 5, Dall'Olio F et al., 2012; Freirede-Lima L, 2014; Julien S et al., 2012; Marcos NT et al., 2004). The Tn, sTn and T 
antigens have been associated with malignant cell phenotypes, disease progression, metastasis and poor prognosis in clinical settings for a variety of different solid tumors (Cazet A et al., 2010; Julien S et al., 2012; Marcos NT et al., 2011; Reis CA et al., 2010a). Recently, we have reported the association between sTn, high-grade bladder cancer and muscle-invasion (Bernardo C et al., 2014; Ferreira JA et al., 2013; Lima L et al., 2013) as well as the capability of $\mathrm{sTn}^{+}$-bladder cancer cells to promote a tolerogenic immune response of dendritic cells (Carrascal MA et al., 2014), demonstrating the involvement of glycans in the mediation of cancer immune responses. The fact that these simple glycans are absent, significantly underexpressed or restricted to some cell types in healthy tissues, renders them potential diagnostic and therapeutic targets. Proteins carrying abnormal glycosylation are often released from the cell-surface, therefore increasing sTn concentrations in the serum (CA72-4 test) of gastric, colorectal and pancreatic carcinoma patients (Carpelan-Holmström M et al., 2004; Reis CA et al., 2010b; Ychou $\mathrm{M}$ et al., 2000) as well as in pre-cancerous gastric lesions (Gomes $\mathrm{C}$ et al., 2013). The elevation of CA72-4 was shown to be an independent prognostic factor in gastric cancer (Louhimo $\mathrm{J}$ et al., 2004) and predictive of tumor recurrence in gastric (Ychou M et al., 2000) as well as pancreatic cancers (Louhimo J et al., 2004). Moreover, monoclonal antibodies have been developed for sTn-MUC1 glycopeptides (Sørensen AL et al., 2006) as well as the therapeutic vaccine Theratope that, despite promising initial results in pre-clinical and in early stage clinical trials for advanced breast tumors (Holmberg LA et al., 2000; Holmberg LA et al., 2004), it remains to be thoroughly assessed in other solid tumors known to overexpress sTn.

Several evidences also point to an increase in the complexity of $N$-linked glycans and glycolipids through $\beta-1,6$ branching, mediated by $\beta-1,6-\mathrm{N}$ acetylglucosaminyltransferase V (Mgat5) in cancer (Figure 5, Fortuna-Costa A et al., 2014; Liu H et al., 2015; Pinho SS et al., 2013; Pinho SS et al., 2011; Taniguchi N et al., 2015). The $\beta-1,6-\mathrm{N}$-acetylglucosamine-branched glycans are responsible to the highaffinity binding of Galectin-3 to several membrane glycoproteins and glycolipids, with implications to angiogenesis, metastasis, and other tumor progression events (FortunaCosta A et al., 2014; Funasaka T et al., 2014). For instance, lysosomal membraneassociated glycoproteins such as (LAMPs)-1and -2, Mac-1 and Mac-3, CD-98, CD-45, and CD-7 as well as EGF, TGF- $\beta$, and VEGF are known ligands for Galectin-3. Galectin-3 also binds CEA and MUC-1, among other relevant cancer-associated 
proteins (Fortuna-Costa A et al., 2014). Galectin-3 crosslinks cell surface glycoprotein receptors resulting in functional microdomains that regulate extracellular signal transduction (Boscher C et al., 2011; Lajoie P et al., 2009), glycoprotein receptor turnover and endocytosis (Lakshminarayan Ret al., 2014). As recently highlighted by several reports (Fortuna-Costa A et al., 2014; Liu FT and Rabinovich GA, 2005; Rabinovich GA and Toscano MA, 2009) galectin-3 mediates several hallmarks of cancer, including tumor growth(Peng W et al., 2008), anoikis resistance (Kim HR et al., 1999), inhibition of apoptosis (Takenaka Y et al., 2004), angiogenesis (Nangia-Makker P et al., 2010), cell adhesion (Khaldoyanidi SK et al., 2003), cell motility (Boscher C and Nabi IR, 2013), cell invasion (Tsuboi K et al., 2007) as well as microenvironment modulation (Nangia-Makker P et al., 2008; Reticker-Flynn NE et al., 2015). Increased $\beta$-1,6-branching of cadherins, integrins and other cytokine/growth factor receptors has also been found to enhance and promote tumor growth and metastasis (Carvalho $\mathrm{S}$ et al., 2015; Granovsky M et al., 2000; Pinho SS et al., 2013; Zhao Y et al., 2008) while the Mgat5 knockout inhibited these phenomena in vitro and in vivo in different experimental cancer models (Carvalho S et al., 2015; Dall'Olio F et al., 2012; FortunaCosta A et al., 2014; Lau KS and Dennis JW, 2008).

Two other common cancer-associated antigens are the $\alpha-2,3$-sialylated forms of type 1 and type 2 Lewis blood group determinants $\mathrm{Le}^{\mathrm{a}}$ and $\mathrm{Le}^{\mathrm{x}}, \mathrm{sLe}^{\mathrm{a}}$ and $\mathrm{sLe}^{\mathrm{x}}$, that may be found as terminal epitopes of glycan chains in both glycoproteins and glycolipids (Carvalho AS et al., 2010; Dall'Olio F et al., 2012; Julien S et al., 2011; Kannagi R, 2007; Tozawa K et al., 2005). These glycans are specific ligands for E- and P-selectins in endothelial cells, two proteins that mediate leukocyte extravasation at sites of tissue injury in a sLe ${ }^{\mathrm{a}} / \mathrm{sLe}^{\mathrm{x}}$-dependent manner (Dall'Olio F et al., 2012). Similarly, these sialylated glycans are thought to act as regulators of the metastatic cascade by promoting endothelial adhesion (Kannagi R, 1997). In addition to a role in metastasis, selectin ligands are also thought to play a role in tumor growth and angiogenesis (Gomes C et al., 2013; Terraneo L et al., 2013). In particular, several reports associate the overexpression of $\mathrm{sLe}^{\mathrm{a}}$ with decreased overall survival in digestive tract tumors (Kannagi R, 2007; Matsui T et al., 2004; Portela SV et al., 2011). Furthermore, serological detection of $\mathrm{SLe}^{\mathrm{a}}$ on glycolipids and glycoproteins by the CA19-9 assay is used as a diagnostic tool to monitor clinical response to therapy for these tumors (Humphris JL et al., 2012; Kannagi R, 2007; Yang GY et al., 2013). Furthermore, the 
2,6-oversialylation of lactosamine chains and overfucosylation of terminal motifs are also among some of the commonly observed structural alterations present in cancer cells (Christiansen $\mathrm{MN}$ et al., 2014). An association between $\alpha$-2,6-sialylation and invasive growth has been suggested by several studies (Dall'Olio F et al., 2014, 2012) and the oversialylation of $\beta$-integrins has been found to modulate intracellular signaling pathways towards increased cell survival (Dall'Olio F et al., 2014). Different mechanisms may account for the above described structural changes, namely alterations in transcription of biosynthetic and degradation enzymes, derangement of secreting organelles and availability of sugar nucleotides, promoted either by microenvironmental stimuli and/or dysfunctional glycogenes (Dall'Olio F et al., 2012; Itzkowitz SH et al., 1989; Reis CA et al., 2010b). Altogether, abnormal glycosylation is considered a typical hallmark of the transition from healthy to neoplastic tissues with direct influence on cell behavior and clinical outcome. More detailed information about the role of glycosylation in cancer may be found in a comprehensive recent review by Pinho and Reis (Pinho SS and Reis CA, 2015). Since alterations in glycosylation take place at the cell-surface resulting in highly distinct protein glycovariants, these present an opportunity for targeted therapeutics. However, as highlighted by recent publications, both similarities and differences exist in the glycosylation patterns of different tumors, mirroring the dynamic nature of the glycome (Christiansen MN et al., 2014). Furthermore, the same glycans may present opposite biological roles in different tumors, denoting the need for a comprehensive analysis of the glycoproteome in a clinical context, towards personalized cancer treatment.

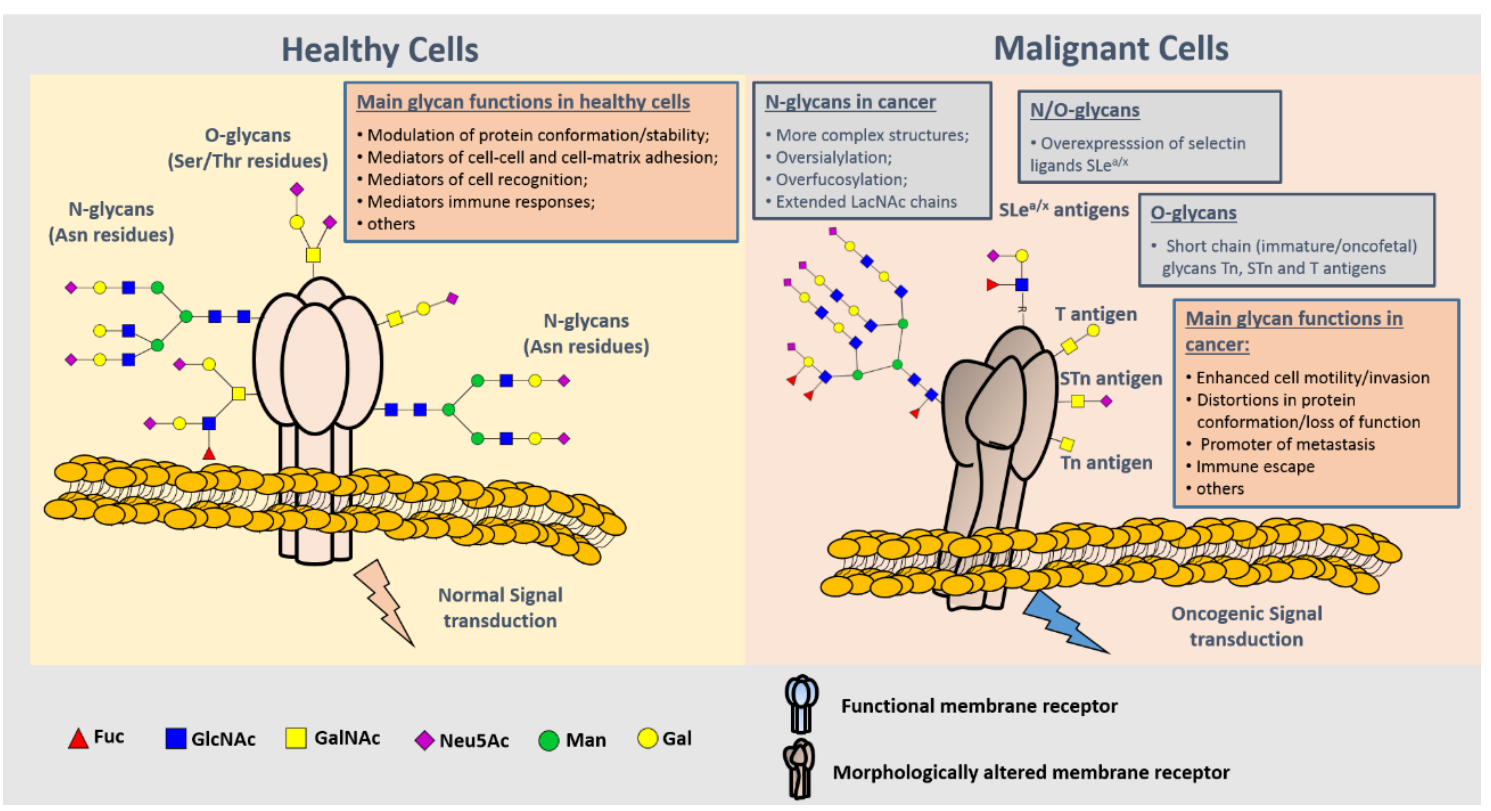




\section{Figure 5 A) Representation of protein $N$ - an $O$-glycosylation in healthy tissues and}

malignant cells. Protein glycosylation plays a key role in the definition of protein folding and physiological functioning. Glycans contribute to cell-cell and cellextracellular matrix adhesion, immune cell recognition, among other key biologic processes. Glycosylation is a highly dynamic posttranslational modification resulting from the concerted and highly regulated action of several glycosyltransferases in secretory organelles that rapidly changes in response to physiological stimuli. Several $N$ - (Asn residues) and $O$ - (Ser/Thr residues) glycans may coexist in the same protein backbone, depending on available glycosites and conformational constrains. In comparison to healthy cells, malignant cells tend to present more complex and branched oversialylated and/or fucosylated $N$-glycans. $N$-glycans may also be more extended by LacNAc chains. Conversely, more malignant clones present less complex and immature $O$-glycans, namely the Tn, sTn and $\mathrm{T}$ antigens that may be also found in oncofetal tissues. Some cancer cells may also express selectin ligands sLea/x as terminal structures of both $\mathrm{N}$ - and $\mathrm{O}$-glycans. These structural alterations at the cellsurface favor more motile and plastic cell phenotypes, invasion, lymphatic and hematogenous dissemination and immune evasion. By impairing normal functions of cell-surface receptors, cancer-associated glycans also interfere with normal intracellular signaling transduction pathways towards the activation of oncogenic features.

\subsection{Protein glycosylation: contribution to chemoresistance}

Several studies have described that subpopulations of multidrug resistant (MDR) cancer cell lines of distinct tissue origin present altered glycosylation patterns, particularly at the $N$-glycosylation level, when compared with the parental cell lines (Beretta GL et al., 2010; Kudo T et al., 2007; Noda I et al., 1999; Schultz MJ et al., 2013; Zhang Z et al., 2012; Zhao Y et al., 2014). Alterations in glycogene expression were also reported and, in most cases, have been found in agreement with the observed glycosylation patterns (Schultz MJ et al., 2013; Zhao Y et al., 2014). In particular, some studies have further associated the overexpression of cell-surface ATP binding cassette transporters (MRP1 and MRP4) and CD147 showing abnormal $N$-glycosylation patterns with drug resistance (Afonso J et al., 2014; Beretta GL et al., 2010). Furthermore, the exposure of chemoresistant cancer cells to tunicamycin, an $\mathrm{N}$-glycosylation biosynthesis 
inhibitor, has been shown to sensitize these cells to anti-cancer agents (Kramer R et al., 1995; Noda I et al., 1999). Although these observations suggest that alterations in $\mathrm{N}$ glycosylation may alter the functional properties of cell-surface transporters involved in multidrug resistance, it should be noticed that tunicamycin is responsible by inducing significant ER stress leading to apoptosis (Han C et al., 2008). Several structural alterations, namely $\alpha$-2,6-oversialylation of cell-surface molecules, have also been shown to significantly modulate downstream oncogenic signaling pathways towards enhanced cell survival, tumor growth and migration (reviewed in detail by Dall'Olio F, et al. and Park J and Lee M) (Dall'Olio F et al., 2014, 2012; Park J and Lee M, 2013). Yet, the contribution of these events to chemotherapy resistance remains to be determined. Adding to these findings, several studies associated elevation of serum sTn antigen (detected by the CA72-4 test) and sLe ${ }^{\text {a }}$ (detected by the CA19-9 test) levels in cancer patients with both recurrence after chemotherapy, metastasis and poor overall survival (Kim DH et al., 2015; Yang GY et al., 2013; Ziske C et al., 2003), suggesting that the presence of these glycans may be associated with drug resistance. However, this hypothesis warrants confirmation in future studies. Altogether, these findings support the notion that glycosylation may constitute a currently neglected posttranslational

modification of proteins which may be associated with cancer chemoresistance. Given its cell-surface nature, in-depth studies of these glycans may allow the selective targeting of these aggressive malignant clones and glycosylation remodeling may constitute a novel approach to overcome chemoresistance.

\section{Chemotherapy challenge and CSC selection: exploring the role of glycosylation for guided therapeutics}

During the last decade, CSC populations were described in various types of solid tumors, albeit their phenotypic and functional characteristics are still under intensive investigation (Tirino V et al., 2013; Visvader JE and Lindeman GJ, 2008). As a result, specific functional features such as self-renewal and long-term repopulation potential were identified in CSC and these characteristics were predominantly related to tumor initiation and maintenance of tumor growth (Al-Hajj M and Clarke MF, 2004). In addition, CSC exhibit a number of genetic and cellular adaptations that confer resistance to conventional chemotherapeutics such as relative dormancy/slow cell cycle kinetics, 
efficient DNA repair, overexpression of multidrug resistance efflux transporters and resistance to apoptosis (Abdullah $\mathrm{LN}$ and Chow EK, 2013; Cojoc $\mathrm{M}$ et al., 2015), as outlined in detail in the previous sections. Furthermore, several reports suggest that conventional therapy often results in enrichment and maintenance of CSC pools that form the tumor after chemotherapy, triggering relapse as chemoresistant tumors. In particular, Levina et al., (Levina V et al., 2008) suggested that cisplatin-containing chemotherapy leads to propagation of human lung cancer stem cells and inhibition of cell differentiation. Moreover, these cells appear to activate an efficient cytokine network that favors their tumorigenic and metastatic potential (Levina V et al., 2008). Other research groups related lung cancer recurrence with maintenance of treatmentselected CSC (Barr MP et al., 2013; Leung EL et al., 2010). For instance, using whole genome expression analysis, Hamilton et al., (Hamilton G and Olszewski U, 2013) demonstrated that small cell lung cancer (SCLC) cells express CSC markers (CD44, CD133, CD47, ALDH1A1, AKR1C), as well as WNT and Notch pathway intermediates after chemo-radiotherapy, compared to treatment-naïve cells. Bertolini et al., also reported that cisplatin treatment spares highly tumorigenic CD $133^{+} \mathrm{NSCLC}^{-}$ cells that display stem-like features (Bertolini G et al., 2009). Zhang Yi et al., found similar correlations in cisplatin-resistant bladder cancer cells, which displayed enhanced self-renewal and tumorigenicity as well as higher levels of sphere formation, a larger proportion of side population cells and stem cell marker expression (Zhang $\mathrm{Y}$ et al., 2012). Regarding ovarian cancer, cisplatin-based chemotherapy also appears to preserve CSC-like cells, resulting in increased tumor burden (Abubaker K et al., 2013; Yasuda K et al., 2013).

These findings support the notion that the combination of conventional chemotherapy directed to bulk tumor cells and targeted strategies against CSC may hold promise to improve cancer management compared to monotherapies. Therefore, over the past decade many concentrated efforts have been put on the isolation and molecular characterization of CSC using chemotherapy selection approaches. In fact, the chronic or acute exposure of tumor cell lines, xenografts and patient samples to anticancer drugs has provided a simple strategy for CSC enrichment, as recently reviewed (Freitas DP et al., 2014). This has allowed the establishment of CSCbiomarker panels, which include, for example, the following proteins: ALDH1, CD29, CD24, CD44, CD90, and CD133 (de Beça FF et al., 2013; Langan RC et al., 2013; Yang $\mathrm{CH}$ et al., 2014). Nevertheless, these biomarker molecules fall short to discern 
cancer from normal adult stem cells, as previously reviewed in detail (Karsten $U$ and Goletz S, 2013), hence prompting the introduction of more specific molecules for targeted therapeutics. Several authors now suggest that targeting oncofetal stem cell markers, normally not present in adult stem cells, may constitute a novel and more effective treatment strategy.

Exploring cancer-associated glycans, which are often of oncofetal nature, presents a unique and highly specific opportunity to target CSC. In fact, several studies reported alterations in the glycopatterns of CSC of different tissue origins compared to other cancer cells. Many of these findings concern the overexpression of glycans commonly found in glycolipids (CD60a, CD77, GD2, Gb4) and proteins (CD147 or Le ${ }^{\mathrm{y}}, \mathrm{CD} 15$ or $\mathrm{Le}^{\mathrm{x}}$ ) (Karsten U and Goletz S, 2013). More recently cumulative evidences confirm that CSC resistant to gemcitabine (Terao $\mathrm{N}$ et al., 2015) and doxorubicin (Azuma $\mathrm{K}$ et al., 2014) present distinct glycosylation patterns when compared to drug sensitive parental cell lines. Namely, Terao et al., described that CSC derived from the gemcitabine chemoresistant pancreatic cancer cell line Panc1 display significant overfucosylation and upregulation of fucosyltransferases, GDP-fucose synthetic enzymes, and GDPfucose transporters (Terao $\mathrm{N}$ et al., 2015). However, knockdown of GDP-fucose transporters did not improve gemcitabine response, suggesting that overfucosylation is a result of CSC transformation with little influence on chemoresistance. On the other hand, Azuma $\mathrm{K}$ et al., explored the oversialylation of doxorubicin-resistant hepatocellular CSC towards the identification of highly specific glycoprotein species (Azuma K et al., 2014). These approaches have contributed to highlight the importance of an in-depth assessment of the glycome and glycoproteome of different CSC populations towards more specific biomarkers.

In this review we emphasize the growing amount of evidence supporting an association between the protein-specific cancer-associated $O$-glycans sTn and T and CSC proteins (Figure 6). The sTn and sialylated $\mathrm{T}$ antigens, which result from a premature arrest in protein glycosylation (as addressed in detail in the previous section), are absent from the majority of healthy tissues, but expressed in several solid tumors (Julien S et al., 2012; Marcos NT et al., 2011; Videira PA et al., 2009). Furthermore, many studies report an increased expression of these proteins in advanced stages of the disease (Julien S et al., 2012). Perhaps the most studied is the sTn antigen (CD72-4), whose presence in adult healthy tissues has been highly restricted to specific cells (Ferreira B et al., 2006; Julien S et al., 2012; Marcos NT et al., 2011). In contrast, the 
sTn antigen has been found overexpressed in many advanced stage solid tumors, where it plays a key role in endowing cancer cells with a metastatic potential; furthermore it is also present in the metastatic lesions (Ferreira B et al., 2006; Julien S et al., 2006; Marcos NT et al., 2011; Pinho S et al., 2007). Although more evidence are required, these findings suggest that sTn-expressing cells may be capable of detaching from the primary tumor and colonize distant tissue locations. Moreover, the sTn antigen was also detected in several fetal organs of both genders (e.g. esophagus, stomach, pancreas, colon, lung, mammary gland, gonadal tissue) (Itzkowitz SH et al., 1989; Julien S et al., 2012; Pistolesi S et al., 2001; Stanick D et al., 1988; Thor A et al., 1986). Although little is known about the biological role of sTn during embryonic development, these evidences suggest that cancer cells undergo, to some extent, similar molecular events. In spite of the possibility of sTn being expressed by all proteins presenting Oglycosylation sites, as demonstrated by several studies using engineered cancer cells to express this antigen (Campos D et al., 2015; Campos et al, 2015b; Julien S et al., 2012), few proteins have emerged from models that naturally express the antigen. Among these proteins are the heavily glycosylated MUC1 (Beatson R et al., 2015; Lakshminarayanan V et al., 2012) and CD44 (Campos D et al., 2015; Carrascal MA et al., 2014; Irimura T et al., 1999; Marcos NT et al., 2011), whose overexpression has been widely observed in CSC of different tumor models (Bourguignon LY et al., 2014; Curry JM et al., 2013; Nath $\mathrm{S}$ et al., 2015). Likewise, Karsten and Goletz discussed a similar role for the $\mathrm{T}$ antigen (CD176) in their recent review on this topic (Karsten U and Goletz S, 2013). Accordingly, this oncofetal antigen has been found in primary tumors and metastases, and detected in CD44 (Lin W et al., 2011; Singh R et al., 2001), CD45 (Baba M et al., 2007), and CD34 (Cao Y et al., 2008) of CSC from different cancer models. 


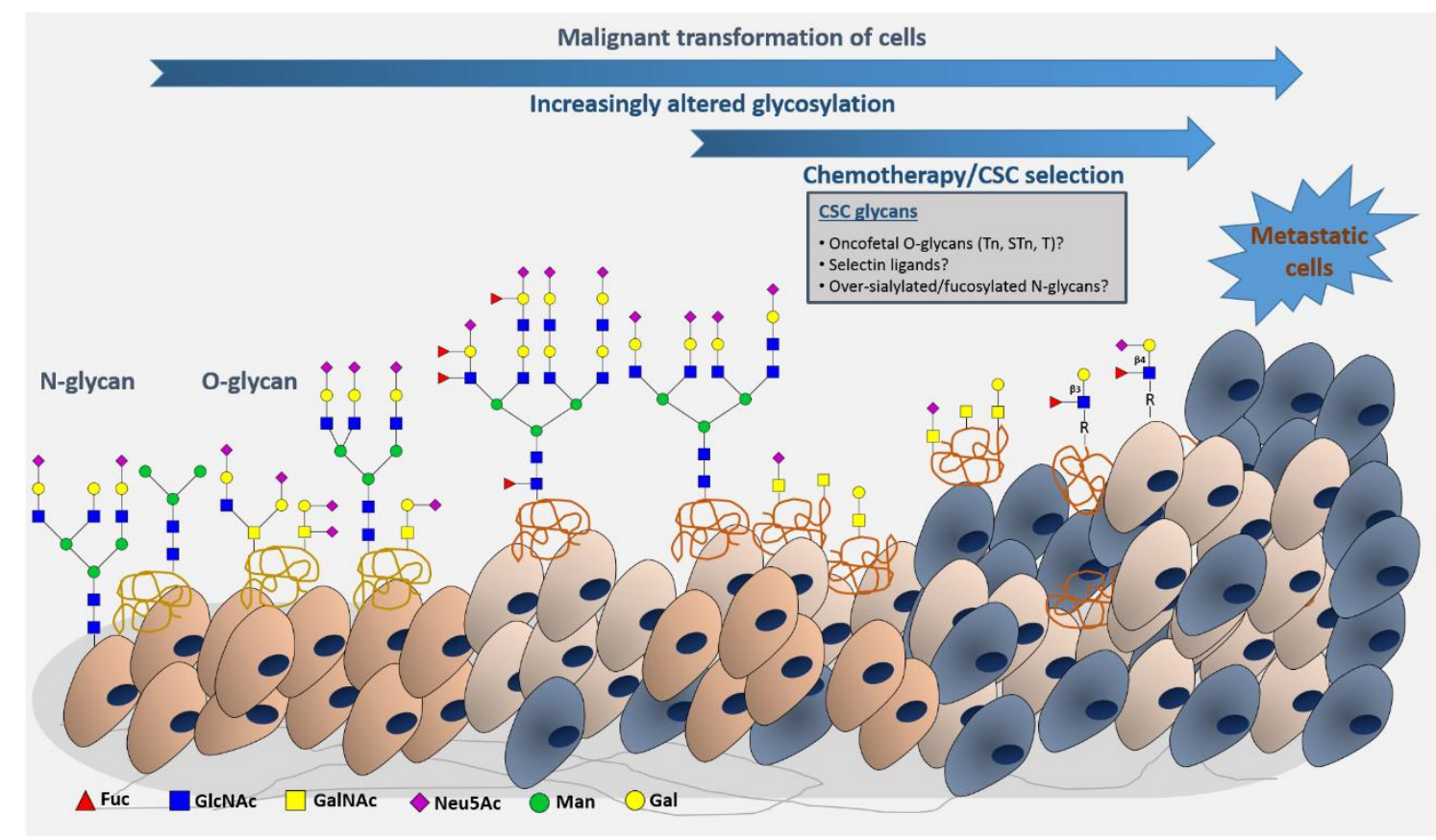

Figure 6. Representation of CSC selection based on chemotherapy with emphasis on cell-surface glycosylation patterns. It has been demonstrated that chemotherapy, while effective against the tumor bulk may promote the selection/development of highly malignant phenotypes, including CSC, responsible for the recapitulation of tumor heterogeneity and ultimately lead to disease dissemination. Increasing evidences support that CSC endowed with chemoresistant properties present distinct proteomes in comparison to more predominant cell populations. Figure 6 illustrates different cancer cells with distinct glycosylation patterns, including oversialylation and fucosylation of both $\mathrm{N}$ - and $\mathrm{O}$-glycans. The selective pressure of chemotherapy towards CSC phenotypes (in blue) and the differentiated nature of CSC glycosylation is also illustrated. The overexpression of oncofetal immature $O$-glycans (Tn, STn, T) and alterations in terminal motifs, namely the overrepresentation of selectin ligands, are amongst the emphasized alterations. A careful glycomic and glycoproteomic evaluation of CSC stemming from chemotherapy challenge may provide unique biomarkers and templates for future drug design.

In summary, while still circumstantial, there is a strong suggestion that the expression of short-chain $O$-glycans is associated with CSC phenotypes. Furthermore, currently there are no direct links between cancer-associated $O$-glycans and chemoresistance. We therefore advocate that a careful investigation of the glycoproteome of CSC focusing on the expression of these fetal glycans may provide 
more specific biomarkers than the currently available panels and provide insights to the possible role of $O$-glycans in chemoresistance.

\section{Concluding Remarks}

Cancer cells show remarkable capability to resist chemotherapy treatments due to the synergistic effect of intrinsic, acquired as well as microenvironmental factors. Moreover, chemotherapy frequently acts as a positive selective pressure for the emergence of more aggressive cell subpopulations such as CSC, which are responsible for promoting disease relapse and progression. While many molecular mechanisms linking chemoresistance and CSC were already identified, CSC targeting remains a challenge, mostly due to the molecular similarities of CSC to non-malignant stem cells. We now comprehensively propose, for the first time, that alterations in protein glycosylation are amongst the key events accompanying and possibly driving chemoresistance. In fact, chemoresistant cancer cells supported by favorable microenvironments and endowed with intracellular mechanisms to evade cell death, present distinct $\mathrm{N}$ - and $\mathrm{O}$-glycosylation patterns when compared to other cancer and non-malignant cells. Moreover, many studies have brought glycosylation into the spotlight by demonstrating that selective inhibition of $N$-glycosylation pathways may constitute an important therapeutic strategy to overcome chemoresistance. However, we argue that the influence of glycosylation extends beyond these events, given that it plays a pivotal role in the activation of several oncogenic pathways that sustain chemoresistance. Despite these insights, a direct link between protein glycosylation and chemoresistance remains to be established. Furthermore, the specific structural nature of CSC-associated glycans and glycoproteins, envisaging highly specific biomarkers has not yet been fully disclosed. Nevertheless, the context-dependent nature of glycans offers tremendous potential for the identification of unique CSC-glycoproteomes and clinically valuable biomarkers for cancer detection and targeted therapeutics.

As cancer treatment is shifting towards precision medicine and patient-tailored strategies (Kohane IS, 2015), we emphasize the need to integrate the patients' background, clinical history, tumor molecular features and the microenvironment in a single holistic perspective. Furthermore, we conclude that it will be imperative to address chemoresistance as a multifactorial and dynamic feature, considering many of the aspects discussed in the current review. Therefore, we come forward with a novel 
model (Figure 7) that incorporates evaluation of glycomics and glycoproteomics in comprehensive pan-omics approaches envisaging more accurate patient stratification, therapy selection, decision and design. Finally, we highlight that effective cancer treatments will likely benefit from multitargeted approaches selected based on a profound knowledge of the molecular nature of the tumor and patient's physiological and pathological status. The choice of treatment schemes and anti-cancer drugs should be dynamic and should Saccount for individual patient's response to treatment towards true precision medicine.

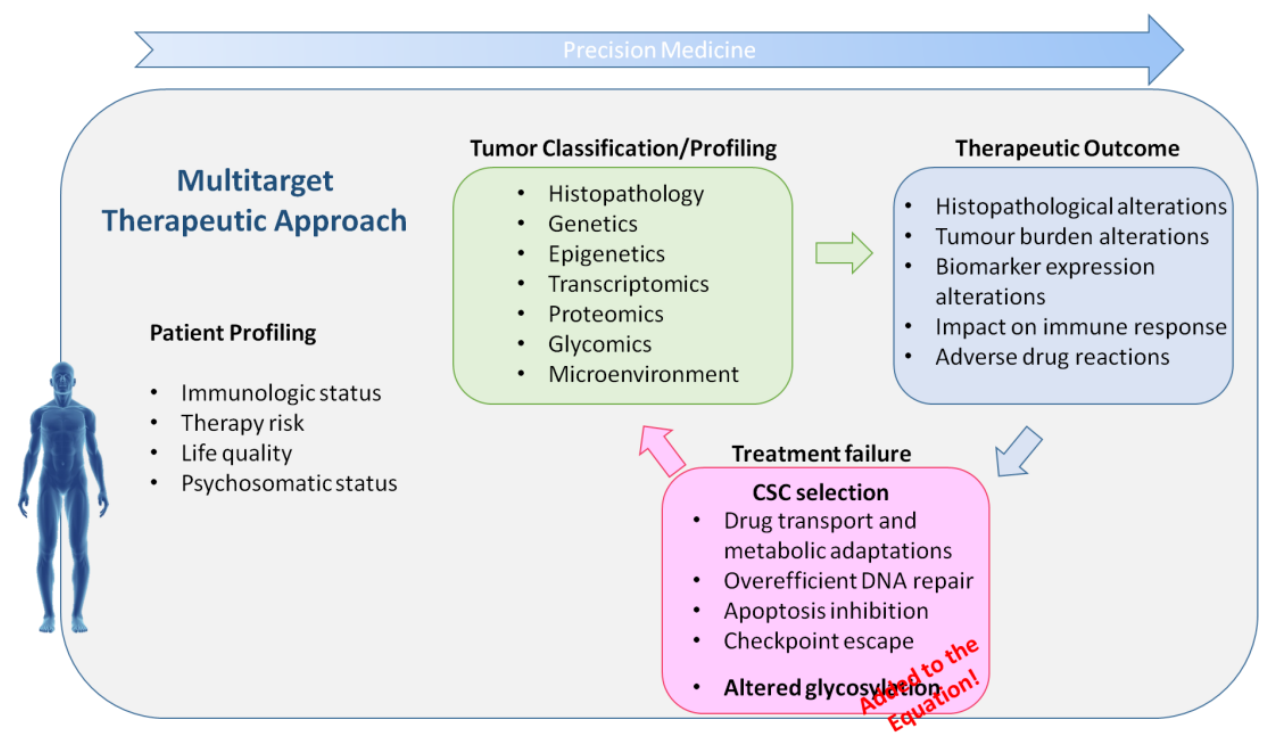

Figure 7. The concept of precision medicine: adding CSC selection to the equation. Effective cancer therapeutics should be based on a dynamic and adaptive decisionmaking process relying on patient's profile, tumor classification and patient's therapeutic outcome towards individualized treatments and improved responses. This process should include therapeutics specifically designed and targeted to CSC, which should allow the overcoming of chemoresistance mechanisms. Altered protein glycosylation may hold potential for novel targeted therapeutics approaches.

\section{Future Perspectives}

This review has highlighted the lack of specific biomarkers to target CSC and the necessity of more effective multi-target anticancer therapeutics to address chemoresistance. We believe that glycoproteins carrying oncofetal glycans, such as the sTn and Tn antigens, and other cancer-associated carbohydrates may help paving the 
way towards more specific targeted therapy. Focus should also be put on a careful and comprehensive glycoproteomic evaluation of chemoresistant clones and their microenvironmental context. These studies will greatly benefit from the tremendous advances, over the past two decades, in the development of highly sensitive massspectrometry platforms and protocols specifically designed to address the complex structural nature of protein glycosylation (Almeida A et al., 2013; Zhang Y et al., 2013). Moreover, while tumor cell lines are important starting models for proof-of-concept studies, it will be important to expand studies towards models able to more accurately mimic the tumor microenvironment. Future approaches should include direct human cancer xenografts in animal models, the so-called avatar models, which have been shown to preserve the molecular features of human tumors, including tumor glycosylation (Aparicio S et al., 2015; Bernardo C et al., 2014; Hidalgo M et al., 2014). New bioengineering approaches such as 3D Lab-on-a-chip settings may also provide the necessary system complexity to address drug toxicity in cancer cells, as demonstrated in several recent publications (Kim C et al., 2015; Ruppen J et al., 2014; Su M et al., 2014).

As already mentioned, true improvements in patient care and chemoresistance require the introduction of multi-target patient-tailored therapeutics. In this context, altered protein glycosylation may constitute the necessary mean to selectively deliver emerging nanotherapeutic agents to cancer cells, thereby improving the efficacy and reducing the toxicity of the treatments (Fernandes E and Ferreira JA et al., 2015; Livney YD and Assaraf YG, 2013). These nanodelivery sytems may include conventional chemotherapy drugs, genetic-based strategies such as the siRNAs against key oncogenic proteins involved in chemoresistance (Ganesh S et al., 2013; Navarro G et al., 2012; QingShuo $\mathrm{M}$ et al., 2013) or the administration of genes capable of rescuing the expression of p53 and other cell cycle checkpoint proteins (Chen GX et al., 2014; Kamal A et al., 2014; Kim SS et al., 2014; Li D et al., 2013). The introduction of antibodies against cancer-associated glycoepitopes may also allow the selective inhibition of oncogenic pathways or the stimulation of immune responses against malignant cells (Azevedo R et al., 2015). Glycan-based therapeutic solutions should also be tested, for the first time, in the context of hematological malignancies that also pose significant chemoresistance issues (Assaraf YG et al., 2014; Assaraf YG, 2007; Gonen N and Assaraf YG, 2012). Nevertheless, the particular differences between blood and epithelial cells should be taken into consideration when designing such strategies. 
In summary, exploiting altered glycosylation for targeted therapeutics is an emerging research topic that holds great potential for overcoming cancer chemoresistance phenomena. However, the roadmap for prototyping glycan-based therapeutics still requires a careful planning addressing the following research topics: i) comprehensive characterization of glycomic and glycoproteomic chemoresistant cells; ii) understanding the biological significance of altered glycosylation in chemoresistance; iii) development of glycan-specific ligands; and iv) establishment of cancer animal models mimicking human glycosylation.

\section{Conflict of interest statement}

None declared

\section{Acknowledgments}

This work was supported by European Union funds (FEDER/COMPETE) and by national funds (FCT, the Portuguese Foundation for Science and Technology) under the projects with the references FCOMP-01-0124-FEDER 028188 (PTDC/BBBEBI/0786/2012) and PTDC/BBB-EBI/0567/2014. C.R. acknowledges the support by Gastric Glyco Explorer Initial Training Network (Seventh Framework Programme grant number 316929). IPATIMUP integrates the i3S Research Unit, which is partially supported by FCT, (PEst-C/SAU/LA0003/2013). Grants were received from FCT: SFRH/BPD/111048/2015 to J.A.F and SFRH/BD/111242/2015 to A.P. FCT is cofinanced by European Social Fund (ESF) under Human Potential Operation Programme (POPH) from National Strategic Reference Framework (NSRF).

\section{References}

Abdullah LN and Chow EK. Mechanisms of chemoresistance in cancer stem cells. Clin Transl Med. 2013; 2:3.

Abubaker K, Latifi A, Luwor R, Nazaretian S, Zhu H, Quinn MA, Thompson EW, Findlay JK, Ahmed N. Short-term single treatment of chemotherapy results in the enrichment of ovarian cancer stem cell-like cells leading to an increased tumor burden. Mol Cancer. 
$2013 ; 12: 24$.

Adamaki M, Georgountzou A and Moschovi M. Cancer and the Cellular Response to Hypoxia. Pediatr. Ther. 2012; S1:002.

Afonso J, Santos LL, Miranda-Gonçalves V, Morais A, Amaro T, Longatto-Filho A, and Baltazar F. CD147 and MCT1-potential partners in bladder cancer aggressiveness and cisplatin resistance. Mol Carcinog. 2014; [Epub ahead of print].

Aggarwal H, Lubana PS, Jain DK, Mathur RK. Estimation of BCL-2 protein in carcinoma of the breast and its clinical correlation in locally advanced breast cancer. J Cancer Res Ther. 2007; 3:207-10.

Ahmad A, Robinson AR, Duensing A, van Drunen E, Beverloo HB, Weisberg DB, Hasty P, Hoeijmakers JH, Niedernhofer LJ. ERCC1-XPF endonuclease facilitates DNA doublestrand break repair. Mol. Cell. Biol. 2008; 28:5082-92.

Akervall J, Xiang G, Q.C., Schoumans J, Leeser B, Kort E, Cole A, Resau J, Bradford C, Carey T, Wennerberg J, Anderson H, Tennvall J, and Teh BT. Genetic and Expression Profiles of Squamous Cell Carcinoma of the Head and Neck Correlate with Cisplatin Sensitivity and Resistance in Cell Lines and Patients. Clin Cancer Res. 2004; 10:8204-8213.

Al-Hajj M and Clarke MF. Self-renewal and solid tumor stem cells. Oncogene. 2004; 23:727482.

Almeida A, Ferreira JA, Teixeira F, Gomes C, Cordeiro MN, Osório H, Santos LL, Reis CA, Vitorino R, Amado F. Challenging the limits of detection of sialylated ThomsenFriedenreich antigens by in-gel deglycosylation and nano-LC-MALDI-TOF-MS. Electrophoresis. 2013; 34:2337-41.

Ansell A, Jerhammar F, Ceder R, Grafström R, Grénman R, Roberg K. Matrix metalloproteinase-7 and -13 expression associate to cisplatin resistance in head and neck cancer cell lines. Oral Oncol. 2009;45:866-71.

Aoudjit F and Vuori K. Integrin Signaling in Cancer Cell Survival and Chemoresistance. Chemother. Res. Pract. 2012; 2012:283181.

Aparicio S, Hidalgo M, and Kung AL. Examining the utility of patient-derived xenograft mouse models. Nat Rev Cancer. 2015;15:311-6.

Arora S, Kothandapani A, Tillison K, Kalman-Maltese V, Patrick SM. Downregulation of XPFERCC1 enhances cisplatin efficacy in cancer cells. DNA Repair (Amst). 2010; 9:745-53.

Ashkenazi A, Holland P, Eckhardt SG. Ligand-based targeting of apoptosis in cancer: the potential of recombinant human apoptosis ligand 2/Tumor necrosis factor-related apoptosis-inducing ligand (rhApo2L/TRAIL). J Clin Oncol. 2008;26:3621-30.

Assaraf YG. Molecular basis of antifolate resistance. Cancer Metastasis Rev. 2007;26:153-81.

Assaraf YG, Leamon CP, Reddy JA. The folate receptor as a rational therapeutic target for personalized cancer treatment. Drug Resist Updat. 2014; 17: 89-95.

Azevedo R, Ferreira JA, Peixoto A, Neves M, Sousa N, Lima A, Santos LL. Emerging antibody-based therapeutic strategies for bladder cancer: A systematic review. J Control 
Release. 2015; 214:40-61.

Azuma K, Serada S, Takamatsu S, Terao N, Takeishi S, Kamada Y, Naka T, Miyoshi E. Identification of sialylated glycoproteins in Doxorubicin-treated hepatoma cells with glycoproteomic analyses. J Proteome Res. 2014; 13:4869-77.

Baba M, Yong Ma B, Nonaka M, Matsuishi Y, Hirano M, Nakamura N, Kawasaki N, Kawasaki $\mathrm{N}$, and Kawasaki T. Glycosylation-dependent interaction of Jacalin with CD45 induces T lymphocyte activation and Th1/Th2 cytokine secretion. J Leukoc Biol. 2007; 81:1002-11.

Barr MP, Gray SG, Hoffmann AC, Hilger RA, Thomale J, O'Flaherty JD, Fennell DA, Richard D, O'Leary JJ, O'Byrne KJ. Generation and Characterisation of Cisplatin-Resistant NonSmall Cell Lung Cancer Cell Lines Displaying a Stem-Like Signature. PLoS One. 2013; 8:e54193.

Basu A and Krishnamurthy S. Cellular responses to Cisplatin-induced DNA damage. J Nucleic Acids. 2010; 2010:201367.

Bauman JE, Austin MC, Schmidt R, Kurland BF, Vaezi A, Hayes DN, Mendez E, Parvathaneni U, Chai X, Sampath S, and Martins RG. ERCC1 is a prognostic biomarker in locally advanced head and neck cancer: results from a randomised, phase II trial. Br J Cancer. 2013;109:2096-105.

Bay BH, Jin R, Huang J, Tan PH. Metallothionein as a prognostic biomarker in breast cancer. Exp Biol Med (Maywood). 2006; 231:1516-21.

Beatson R, Maurstad G, Picco G, Arulappu A, Coleman J, Wandell HH, Clausen H, Mandel U, Taylor-Papadimitriou J, Sletmoen M, Burchell JM. The Breast Cancer-Associated Glycoforms of MUC1, MUC1-Tn and sialyl-Tn, Are Expressed in COSMC Wild-Type Cells and Bind the C-Type Lectin MGL. PLoS One. 2015; 10:e0125994.

Beers MF, Zhao M, Tomer Y, Russo SJ, Zhang P, Gonzales LW, Guttentag SH, and Mulugeta $\mathrm{S}$. Disruption of N-linked glycosylation promotes proteasomal degradation of the human ATP-binding cassette transporter ABCA3. Am. J. Physiol. Lung Cell. Mol. Physiol. 2013; 305:L970-80.

Belyanskaya LL, Hopkins-Donaldson S, Kurtz S, Simões-Wüst AP, Yousefi S, Simon HU, Stahel R, and Zangemeister-Wittke U. Cisplatin activates Akt in small cell lung cancer cells and attenuates apoptosis by survivin upregulation. Int. J. Cancer. 2005; 117:755-763.

Beretta GL, Benedetti V, Cossa G, Assaraf YG, Bram E, Gatti L, Corna E, Carenini N, Colangelo D, Howell SB, Zunino F, Perego P. Increased levels and defective glycosylation of MRPs in ovarian carcinoma cells resistant to oxaliplatin. Biochem Pharmacol. 2010; 79: $1108-17$.

Bernardo C, Costa C, Amaro T, Gonçalves M, Lopes P, Freitas R, Gärtner F, Amado F, Ferreira JA, Santos L. Patient-derived sialyl-Tn-positive invasive bladder cancer xenografts in nude mice: an exploratory model study. Anticancer Res. 2014; 34:735-44.

Bertolini G, Roz L, Perego P, Tortoreto M, Fontanella E, Gatti L, Pratesi G, Fabbri A, Andriani F, Tinelli S, Roz E, Caserini R, Lo Vullo S, Camerini T, Mariani L, Delia D, Calabrò E, Pastorino U, and Sozzi G. Highly tumorigenic lung cancer CD133+ cells display stem-like 
features and are spared by cisplatin treatment. Proc Natl Acad Sci U S A. 2009; 106:16281-6.

Bérubé M, Talbot M, Collin C, Paquet-Bouchard C, Germain L, Guérin SL, Petitclerc E. Role of the extracellular matrix proteins in the resistance of SP6.5 uveal melanoma cells toward cisplatin. Int. J. Oncol. 2005; 26:405-413.

Blons H, Gad S, Zinzindohoué F, Manière I, Beauregard J, Tregouet D, Brasnu D, Beaune P, Laccourreye O, Laurent-Puig P. Matrix metalloproteinase 3 polymorphism: a predictive factor of response to neoadjuvant chemotherapy in head and neck squamous cell carcinoma. Clin. Cancer Res. 2004; 10:2594-2599.

Borst P, Evers R, Kool M, Wijnholds J. A family of drug transporters: the multidrug resistanceassociated proteins. J Natl Cancer Inst. 2000; 92:1295-1302.

Boscher C and Nabi IR. Galectin-3- and phospho-caveolin-1-dependent outside-in integrin signaling mediates the EGF motogenic response in mammary cancer cells. Mol Biol Cell. $2013 ; 24: 2134-45$.

Boscher C, Dennis JW, Nabi IR. Glycosylation, galectins and cellular signaling. Curr Opin Cell Biol. 2011; 23:383-92.

Bourguignon LY, Shiina M, Li JJ. Hyaluronan-CD44 interaction promotes oncogenic signaling, microRNA functions, chemoresistance, and radiation resistance in cancer stem cells leading to tumor progression. Adv Cancer Res. 2014; 123:255-75.

Bourguignon LY, Wong G, Earle C, Chen L. Hyaluronan-CD44v3 interaction with Oct4-Sox2Nanog promotes miR-302 expression leading to self-renewal, clonal formation, and cisplatin resistance in cancer stem cells from head and neck squamous cell carcinoma. $\mathrm{J}$ Biol Chem. 2012; 287:32800-24.

Boussios S, Pentheroudakis G, Katsanos K, Pavlidis N. Systemic treatment-induced gastrointestinal toxicity: Incidence, clinical presentation and management. Ann Gastroenterol. 2012; 25:106-118.

Bradbury PA, Kulke MH, Heist RS, Zhou W, Ma C, Xu W, Marshall AL, Zhai R, Hooshmand SM, Asomaning K, Su L, Shepherd FA, Lynch TJ, Wain JC, Christiani DC, Liu G. Cisplatin pharmacogenetics, DNA repair polymorphisms, and esophageal cancer outcomes. Pharmacogenet Genomics . 2009; 19:613-25.

Bremnes RM, Dønnem T, Al-Saad S, Al-Shibli K, Andersen S, Sirera R, Camps C, Marinez I, Busund L. The Role of Tumor Stroma in Cancer Progression and Prognosis. J. Thorac. Oncol. 2011; 6:209-217.

Brennemann W, Stoffel-Wagner B, Helmers A, Mezger J, Jäger N, Klingmüller D. Gonadal function of patients treated with cisplatin based chemotherapy for germ cell cancer. J Urol. 1997; 158:844-50.

Brennen WN, Isaacs JT, Denmeade SR. Rationale Behind Targeting Fibroblast Activation Protein- Expressing Carcinoma-Associated Fibroblasts as a Novel Chemotherapeutic Strategy. Mol Cancer Ther. 2012; 11:257-266.

Brocato J, Chervona Y, and Costa M. Molecular responses to hypoxia-inducible factor $1 \alpha$ and 
beyond. Mol. Pharmacol. 2014; 85:651-7.

Brockhausen I, Schachter H, and Stanley P, 2009. O-GalNAc Glycans, in: In: Varki A, Cummings RD, Esko JD, et Al., Editors. Essentials of Glycobiology. 2nd Edition. p. Chapter 9.

Buckley NE, Mullan PB. BRCA1--conductor of the breast stem cell orchestra: the role of BRCA1 in mammary gland development and identification of cell of origin of BRCA1 mutant breast cancer. Stem Cell Rev. 2012; 8:982-93.

Campos D, Freitas D, Gomes J, Magalhães A, Steentoft C, Gomes C, Vester-Christensen MB, Ferreira JA, Afonso LP, Santos LL, Pinto de Sousa J, Mandel U, Clausen H, Vakhrushev SY, Reis CA. Probing the O-glycoproteome of Gastric Cancer Cell Lines for Biomarker Discovery. Mol Cell Proteomics. 2015; 14:1616-29.

Campos D, Freitas D, Gomes J, Reis CA. Glycoengineered cell models for the characterization of cancer O-glycoproteome: an innovative strategy for biomarker discovery. Expert Rev Proteomics. 2015; 12:337-42.

Cao Y, Merling A, Karsten U, Goletz S, Punzel M, Kraft R, Butschak G, Schwartz-Albiez R. Expression of CD175 (Tn), CD175s (sialosyl-Tn) and CD176 (Thomsen-Friedenreich antigen) on malignant human hematopoietic cells. Int J Cancer. 2008; 123:89-99.

Carpelan-Holmström M, Louhimo J, Stenman UH, Alfthan H, Järvinen H, Haglund C. Estimating the probability of cancer with several tumor markers in patients with colorectal disease. Oncology. 2004; 66:296-302.

Carrascal MA, Severino PF, Guadalupe Cabral M, Silva M, Ferreira JA, Calais F, Quinto H, Pen C, Ligeiro D, Santos LL, Dall'Olio F, Videira PA. Sialyl Tn-expressing bladder cancer cells induce a tolerogenic phenotype in innate and adaptive immune cells. Mol Oncol. 2014; 8:753-65.

Carvalho AS, Harduin-Lepers A, Magalhães A, Machado E, Mendes N, Costa LT, Matthiesen R, Almeida R, Costa J, Reis CA. Differential expression of alpha-2,3-sialyltransferases and alpha-1,3/4-fucosyltransferases regulates the levels of sialyl Lewis a and sialyl Lewis $\mathrm{x}$ in gastrointestinal carcinoma cells. Int J Biochem Cell Biol. 2010; 42:80-9.

Carvalho S, Catarino TA, Dias AM, Kato M, Almeida A, Hessling B, Figueiredo J, Gärtner F, Sanches JM, Ruppert T, Miyoshi E, Pierce M, Carneiro F, Kolarich D, Seruca R, Yamaguchi Y, Taniguchi N, Reis CA, Pinho SS. Preventing E-cadherin aberrant Nglycosylation at Asn-554 improves its critical function in gastric cancer. Oncogene.2015; [Epub ahead of print].

Casares C, Ramírez-Camacho R, Trinidad A, Roldán A, Jorge E, García-Berrocal JR. Reactive oxygen species in apoptosis induced by cisplatin: review of physiopathological mechanisms in animal models. Eur Arch Otorhinolaryngol. 2012; 269:2455-9.

Cazet A, Julien S, Bobowski M, Burchell J, and Delannoy P. Tumour-associated carbohydrate antigens in breast cancer. Breast Cancer Res. 2010; 12:204.

Chen GX, Zhang S, He XH, Liu SY, Ma C, Zou XP. Clinical utility of recombinant adenoviral human p53 gene therapy : current perspectives. Onco Targets Ther. 2014; 7:1901-9. 
Chen HHW and Kuo MT. Role of glutathione in the regulation of Cisplatin resistance in cancer chemotherapy. Met. Based. Drugs. 2010; 2010:430939.

Chen Y, Wang Y, Fu C, Diao F, Song L, Li Z, Yang R and Lu J. Dexamethasone enhances cell resistance to chemotherapy by increasing adhesion to extracellular matrix in human ovarian cancer cells. Endocr. Relat. Cancer. 2010; 17:39-50.

Chen ZS, Mutoh M, Sumizawa T, Furukawa T, Haraguchi M, Tani A, Saijo N, Kondo T, Akiyama S. An Active Efflux System for Heavy Metals in Cisplatin-Resistant Human KB Carcinoma Cells. Exp. Cell Res. 1998; 240:312-20.

Choi I, Strauss R, Richter M, Yun C, Lieber A. Strategies to increase drug penetration in solid tumors. Front. Oncol. 2013; 3:193.

Christiansen MN, Chik J, Lee L, Anugraham M, Abrahams JL, Packer NH. Cell surface protein glycosylation in cancer. Proteomics. 2014; 14:525-46.

Church DN and Talbot DC. Survivin in solid tumors: rationale for development of inhibitors. Curr Oncol Rep. 2012;14:120-8.

Clodfelter JE, B Gentry M, Drotschmann K. MSH2 missense mutations alter cisplatin cytotoxicity and promote cisplatin-induced genome instability. Nucleic Acids Res. 2005; 33: 3323-30.

Cojoc M, Mäbert K, Muders MH, Dubrovska A. A role for cancer stem cells in therapy resistance: Cellular and molecular mechanisms. Semin. Cancer Biol. 2015; 31:16-27.

Comerford KM, Wallace TJ, Karhausen J, Louis NA, Montalto MC, and Colgan SP. Hypoxiainducible Factor-1-dependent Regulation of the Multidrug Resistance. Cancer Res. 2002; 62:3387-94.

Courtois S, Verhaegh G, North S, Luciani MG, Lassus P, Hibner U, Oren M, and Hainaut P. DeltaN-p53, a natural isoform of p53 lacking the first transactivation domain, counteracts growth suppression by wild-type p53. Oncogene. 2002; 21:6722-8.

Crea F, Duhagon MA, Farrar WL, Danesi R. Pharmacogenomics and cancer stem cells: A changing landscape? Trends Pharmacol. Sci. 2011; 32:487-94.

Curry JM, Thompson K, Rao SG, Besmer DM, Murphy AM, Grdzelishvili VZ, Ahrens WA, McKillop IH, Sindram D, Iannitti DA, Martinie JB, and Mukherjee P. The use of a novel MUC1 antibody to identify cancer stem cells and circulating MUC1 in mice and patients with pancreatic cancer. J Surg Oncol. 2013; 107:713-22.

Dabrowiak JC, Goodisman J, Souid AK, 2002. Kinetic Study of the Reaction of Cisplatin With Thiols. Drug Metab Dispos. 2002; 30:1378-1384.

Dall'Olio F, Malagolini N, Trinchera M, Chiricolo M. Sialosignaling: sialyltransferases as engines of self-fueling loops in cancer progression. Biochim Biophys Acta. 2014; 1840:2752-64.

Dall'Olio F, Malagolini N, Trinchera M, Chiricolo M. Mechanisms of cancer-associated glycosylation changes. Front Biosci (Landmark Ed). 2012; 17:670-99.

Dasari S and Tchounwou PB. Cisplatin in cancer therapy: molecular mechanisms of action. Eur 
J Pharmacol. 2014; 740:364-78.

de Beça FF, Caetano P, Gerhard R, Alvarenga CA, Gomes M, Paredes J, Schmitt F. Cancer stem cells markers CD44, CD24 and ALDH1 in breast cancer special histological types. J Clin Pathol. 2013; 66:187-91.

de Kruijf EM, van Nes JG, van de Velde CJ, Putter H, Smit VT, Liefers GJ, Kuppen PJ, Tollenaar RA, Mesker WE. Tumor-stroma ratio in the primary tumor is a prognostic factor in early breast cancer patients, especially in triple-negative carcinoma patients. Breast Cancer Res Treat. 2011; 125:687-96.

Deng CX and Wang RH. Roles of BRCA1 in DNA damage repair: a link between development and cancer. Hum Mol Genet. 2003; 12:R113-R123.

Denko NC, Fontana LA, Hudson KM, Sutphin PD, Raychaudhuri S, Altman R and Giaccia AJ. Investigating hypoxic tumor physiology through gene expression patterns. Oncogene. 2003; 22:5907-14.

Dhillon KK, Swisher EM and Taniguchi T. Secondary mutations of BRCA1/2 and drug resistance. Cancer Sci. 2011; 102:663-69.

Dobbin ZC, Katre AA, Steg AD, Erickson BK, Shah MM, Alvarez RD, Conner MG, Schneider $\mathrm{D}$, Chen D and Landen CN. Using heterogeneity of the patient-derived xenograft model to identify the chemoresistant population in ovarian cancer. Oncotarget. 2014; 5:8750-64.

Drayton RM and Catto JW. Molecular mechanisms of cisplatin resistance in bladder cancer. Expert Rev Anticancer Ther. 2012; 12:271-81.

Eberle KE, Sansing HA, Szaniszlo P, Resto VA, Berrier AL. Carcinoma matrix controls resistance to cisplatin through talin regulation of NF-kB. PLoS One. 2011; 6:e21496.

Elenbaas B and Weinberg RA. Heterotypic signaling between epithelial tumor cells and fibroblasts in carcinoma formation. Exp Cell Res. 2001; 264:169-84.

Ertan E, Soydinc H, Yazar A, Ustuner Z, Tas F, Yasasever V. Matrix metalloproteinase-9 decreased after chemotherapy in patients with non-small cell lung cancer. Tumori. 2011; 97:286-289.

Feizi T. Demonstration by monoclonal antibodies that carbohydrate structures of glycoproteins and glycolipids are onco-developmental antigens. Nature. 1985; 314:53-7.

Fernandes E and Ferreira JA, Peixoto A, Lima L, Barroso S, Sarmento B, Santos LL. New trends in guided nanotherapies for digestive cancers: A systematic review. J Control Release. 2015; 209:288-307.

Ferreira B, Marcos NT, David L, Nakayama J, Reis CA. Terminal 1,4-linked Nacetylglucosamine in Helicobacter pylori-associated Intestinal Metaplasia of the Human Stomach and Gastric Carcinoma Cell Lines. J Histochem Cytochem. 2006; 54:585-91.

Ferreira JA, Videira PA, Lima L, Pereira S, Silva M, Carrascal M, Severino PF, Fernandes E, Almeida A, Costa C, Vitorino R, Amaro T, Oliveira MJ, Reis CA, Dall'Olio F, Amado F, Santos LL. Overexpression of tumour-associated carbohydrate antigen sialyl-Tn in advanced bladder tumours. Mol Oncol. 2013; 7:719-31. 
Fischer C, Leithner K, Wohlkoenig C, Quehenberger F, Bertsch A, Olschewski A, Olschewski $\mathrm{H}$ and Hrzenjak A. Panobinostat reduces hypoxia-induced cisplatin resistance of non-small cell lung carcinoma cells via HIF-1 $\alpha$ destabilization. Mol. Cancer. 2015; 14:4.

Flores ER, Sengupta S, Miller JB, Newman JJ, Bronson R, Crowley D, Yang A, McKeon F, Jacks T. Tumor predisposition in mice mutant for p63 and p73: evidence for broader tumor suppressor functions for the p53 family. Cancer Cell. 2005; 7:363-73.

Flores ER, Tsai KY, Crowley D, Sengupta S, Yang A, McKeon F, Jacks T. p63 and p73 are required for p53-dependent apoptosis in response to DNA damage. Nature. 2002; 416:560-4.

Fortuna-Costa A, Gomes AM, Kozlowski EO, Stelling MP, and Pavão MS. Extracellular Galectin-3 in Tumor Progression and Metastasis. Front Oncol. 2014; 4:138.

Franco OE and Hayward SW. Targeting the tumor stroma as a novel therapeutic approach for prostate cancer. Adv Pharmacol. 2012; 65:267-313.

Frank NY, Schatton T, and Frank MH. The therapeutic promise of the cancer stem cell concept. J Clin Invest. 2010; 120:41-50.

Freire-de-Lima L. Sweet and Sour: The Impact of Differential Glycosylation in Cancer Cells Undergoing Epithelial-Mesenchymal Transition. Front Oncol. 2014; 4:59.

Freitas DP, Teixeira CA, Santos-Silva F, Vasconcelos MH, and Almeida GM. Therapy-induced enrichment of putative lung cancer stem-like cells. Int J Cancer. 2014; 134:1270-8.

Fu S, Naing A, Fu C, Kuo MT, Kurzrock R. Overcoming platinum resistance through the use of a copper-lowering agent. Mol. Cancer Ther. 2012; 11:1221-5.

Fujiwara Y, Sugimoto Y, Kasahara K, Bungo M, Yamakido M, Tew KD, Saijo N. Determinants of drug response in a cisplatin-resistant human lung cancer cell line. Jpn J Cancer Res. 1990; 81:527-35.

Fulda S. Regulation of apoptosis pathways in cancer stem cells. Cancer Lett. 2013; 338:168-73.

Funasaka T, Raz A, and Nangia-Makker P. Galectin-3 in angiogenesis and metastasis. Glycobiology. 2014; 24:886-91.

Gadducci A, Cosio S, Muraca S, Genazzani AR. Molecular mechanisms of apoptosis and chemosensitivity to platinum and paclitaxel in ovarian cancer: biological data and clinical implications. Eur J Gynaecol Oncol. 2002; 25:390-6.

Gallia GL, Tyler BM, Hann CL, Siu IM, Giranda VL, Vescovi AL, Brem H, and Riggins GJ. Inhibition of Akt inhibits growth of glioblastoma and glioblastoma stem-like cells. Mol Cancer Ther. 2009; 8:386-93.

Galluzzi L, Senovilla L, Vitale I, Michels J, Martins I, Kepp O, Castedo M, Kroemer G. Molecular mechanisms of cisplatin resistance. Oncogene. 2012; 31:1869-83.

Ganesh S, Iyer AK, Weiler J, Morrissey DV, and Amiji MM. Combination of siRNA-directed Gene Silencing With Cisplatin Reverses Drug Resistance in Human Non-small Cell Lung Cancer. Mol Ther Nucleic Acids. 2013; 2:e110. 
Gansukh T, Donizy P, Halon A, Lage H, Surowiak P. In vitro analysis of the relationships between metallothionein expression and cisplatin sensitivity of non-small cellular lung cancer cells. Anticancer Res. 2013; 33:5255-60.

Gill DJ, Tham KM, Chia J, Wang SC, Steentoft C, Clausen H, Bard-Chapeau EA, Bard FA. Initiation of GalNAc-type O-glycosylation in the endoplasmic reticulum promotes cancer cell invasiveness. Proc Natl Acad Sci U S A. 2013; 110:E3152-61.

Gogna R, Madan E, Kuppusamy P, Pati U. Re-oxygenation causes hypoxic tumor regression through restoration of p53 wild-type conformation and post-translational modifications. Cell Death Dis. 2012; 3:e286.

Gomes C, Almeida A, Ferreira JA, Silva L, Santos-Sousa H, Pinto-de-Sousa J, Santos LL, Amado F, Schwientek T, Levery SB, Mandel U, Clausen H, David L, Reis CA, Osório H. Glycoproteomic analysis of serum from patients with gastric precancerous lesions. J Proteome Res. 2013;12:1454-66.

Gomes C, Osório H, Pinto MT, Campos D, Oliveira MJ, Reis CA. Expression of ST3GAL4 leads to $\operatorname{SLe}(\mathrm{x})$ expression and induces c-Met activation and an invasive phenotype in gastric carcinoma cells. PLoS One. 2013; 8:e66737.

Gonen N and Assaraf YG. Antifolates in cancer therapy: structure, activity and mechanisms of drug resistance. Drug Resist Updat. 2012; 15:183-210.

Granovsky M, Fata J, Pawling J, Muller WJ, Khokha R, and Dennis JW. Suppression of tumor growth and metastasis in Mgat5-deficient mice. Nat Med. 2000; 6:306-12.

Greijer AE and Van der Wall E. The role of hypoxia inducible factor 1 (HIF-1) in hypoxia induced apoptosis. J. Clin. Pathol. 2004; 57:1009-14.

Guillou L, Estreicher A, Chaubert P, Hurlimann J, Kurt AM, Metthez G, Iggo R, Gray AC, Jichlinski P, Leisinger HJ, and Benhattar J. Germ cell tumors of the testis overexpress wild-type p53. Am J Pathol. 1996;149:1221-1228.

Guminski AD, Balleine RL, Chiew YE, Webster LR, Tapner M, Farrell GC, Harnett PR, Defazio A. MRP2 ( ABCC2 ) and cisplatin sensitivity in hepatocytes and human ovarian carcinoma. Gynecol. Oncol. 2006; 100:239-246.

Hakomori S. Aberrant glycosylation in tumors and tumor-associated carbohydrate antigens. Adv Cancer Res. 1989; 52:257-331.

Hale MD, Hayden JD, Grabsch HI. Tumour-microenvironment interactions: role of tumour stroma and proteins produced by cancer-associated fibroblasts in chemotherapy response. Cell. Oncol. 2013; 36:95-112.

Hałoń A, Nowak-Markwitz E, Donizy P, Matkowski R, Maciejczyk A, Gansukh T, Györffy B, Spaczyński M, Zabel M, Lage H, Surowiak P. Enhanced immunoreactivity of TIMP-2 in the stromal compartment of tumor as a marker of favorable prognosis in ovarian cancer patients. J Histochem Cytochem. 2012;60:491-501.

Haltiwanger RS, Lowe JB. Role of glycosylation in development. Annu Rev Biochem. 2004; 73: 491-537. 
Hamilton G and Olszewski U. Chemotherapy-induced Enrichment of Cancer Stem Cells in Lung Cancer. J Bioanal Biomed. 2013; S9:003.

Han C, Nam MK, Park HJ, Seong YM, Kang S, and Rhim H. Tunicamycin-induced ER stress upregulates the expression of mitochondrial $\mathrm{HtrA} 2$ and promotes apoptosis through the cytosolic release of HtrA2. J Microbiol Biotechnol. 2008; 18:1197-202.

Hara I, Miyake H, Hara S, Arakawa S, and Kamidono S. Significance of matrix metalloproteinases and tissue inhibitors of metalloproteinase expression in the recurrence of superficial transitional cell carcinoma of the bladder. J. Urol. 2001; 165:1769-72.

Harris AL. Hypoxia-a key regulatory factor in tumour growth. Nat. Rev. Cancer. 2002; 2:38-47.

Hasegawa T, Yashiro M, Nishii T, Matsuoka J, Fuyuhiro Y, Morisaki T, Fukuoka T, Shimizu K, Shimizu T, Miwa A, Hirakawa K. Cancer-associated fibroblasts might sustain the stemness of scirrhous gastric cancer cells via transforming growth factor- $\beta$ signaling. Int $\mathrm{J}$ Cancer. 2014; 134:1785-95.

Häuselmann I and Borsig L. Altered tumor-cell glycosylation promotes metastasis. Front. Oncol. 2014; 4:28.

He YC, Zhou FL, Shen Y, Liao DF, and Cao D. Apoptotic death of cancer stem cells for cancer therapy. Int J Mol Sci. 2014; 15:8335-51.

Henkels KM and Turchi JJ. Cisplatin-induced apoptosis proceeds by caspase-3-dependent andindependent pathways in cisplatin-resistant and-sensitive human ovarian cancer cell lines. Cancer Res. 1999; 59:3077-83.

Hidalgo M, Amant F, Biankin AV, Budinská E, Byrne AT, Caldas C, Clarke RB, de Jong S, Jonkers J, Mælandsmo GM, Roman-Roman S, Seoane J, Trusolino L, and Villanueva A. Patient Derived Xenograft Models: An Emerging Platform for Translational Cancer Research. Cancer Discov. 2014; 4:998-1013.

Hishikawa Y, Kohno H, Ueda S, Kimoto T, Dhar DK, Kubota H, Tachibana M, Koji T, Nagasue N. Expression of metallothionein in colorectal cancers and synchronous liver metastases. Oncology. 2001; 61:162-7.

Hockel M and Vaupel P. Tumor Hypoxia: Definitions and Current Clinical , Biological, and Molecular Aspects. J. Natl. Cancer Inst. 2001; 93:266-276.

Hodkinson PS, Mackinnon AC, Sethi T. Extracellular matrix regulation of drug resistance in small-cell lung cancer. Int J Radiat Biol. 2007; 83:733-41.

Holmberg LA, Oparin DV, Gooley T, Lilleby K, Bensinger W, Reddish MA, MacLean GD, Longenecker BM, and Sandmaier BM. Clinical outcome of breast and ovarian cancer patients treated with high-dose chemotherapy, autologous stem cell rescue and THERATOPE ® STn-KLH cancer vaccine. Bone Marrow Transplant. 2000; 25:1233-41.

Holmberg LA, Sandmaier BM. Vaccination with Theratope (STn-KLH) as treatment for breast cancer. Expert Rev Vaccines. 2004; 3:655-63.

Holzer AK, Katano K, Klomp LWJ, Howell SB. Cisplatin Rapidly Down-regulates Its Own Influx Transporter hCTR1 in Cultured Human Ovarian Carcinoma Cells. Clin. cancer Res. 
2004; 10:6744-6749.

Howell SB, Safaei R, Larson CA, Sailor MJ. Copper transporters and the cellular pharmacology of the platinum-containing cancer drugs. Mol. Pharmacol. 2010; 77:887-894.

Huang LA, Bindra RS, Glazer PM, Harris AL. Hypoxia-induced genetic instability--a calculated mechanism underlying tumor progression. J Mol Med. 2007; 85:139-48.

Humphris JL, Chang DK, Johns AL, Scarlett CJ, Pajic M, Jones MD, Colvin EK, Nagrial A, Chin VT, Chantrill LA, Samra JS, Gill AJ, Kench JG, Merrett ND, Das A, Musgrove EA, Sutherland RL, and Biankin AV. The prognostic and predictive value of serum CA19.9 in pancreatic cancer. Ann Oncol. 2012; 23:1713-22.

Husain A, He G, Venkatraman ES, and Spriggs DR. BRCA1 Up-Regulation Is Associated with Repair-mediated m-Diamminedichloroplatinum(II)1. Cancer Res. 1998; 58:1120-3.

Hussain A, Harish G, Prabhu SA, Mohsin J, Khan MA, Rizvi TA, Sharma C. Inhibitory effect of genistein on the invasive potential of human cervical cancer cells via modulation of matrix metalloproteinase- 9 and tissue inhibitors of matrix metalloproteinase- 1 expression. Cancer Epidemiol. 2012; 36:e387-93.

Irimura T, Denda K, Iida Si, Takeuchi H, and Kato K. Diverse Tumor Glycosylation of MUC1 and Potential Significance in Tumor Immunity. J Biochem. 1999; 126:975-85.

Ishida S, McCormick F, Smith-McCune K, and Hanahan D. Enhancing tumor-specific uptake of the anticancer drug cisplatin with a copper chelator. Cancer Cell. 2010; 17:574-583.

Ishikawa $\mathrm{T}$ and Ali-Osman $\mathrm{F}$. Glutathione-associated cis-Diamminedichloroplatinum (II) Metabolism and ATP-dependent Efflux from Leukemia Cells. J Biol Chem. 1993; 268:20116-125.

Ishikawa $\mathrm{T}$, Wright $\mathrm{CD}$, Ishizuka $\mathrm{H}$. GS-X pump is functionally overexpressed in cisdiamminedichloroplatinum (II)-resistant human leukemia HL-60 cells and down-regulated by cell differentiation. J Biol Chem. 1994; 269:29085-93.

Itzkowitz SH, Yuan M, Montgomery CK, Kjeldsen T, Takahashi HK, Bigbee WL, Kim YS. Expression of Tn, Sialosyl-Tn, and T Antigens in Human Colon Cancer. Cancer Res. 1989; 49:197-204.

James CR, Quinn JE, Mullan PB, Johnston PG, Harkin DP. BRCA1, a potential predictive biomarker in the treatment of breast cancer. Oncologist. 2007; 12:142-150.

Januchowski R, Zawierucha P, Rucinski M, Nowicki M, and Zabel M. Extracellular Matrix Proteins Expression Profiling in Chemoresistant Variants of the A2780 Ovarian Cancer Cell Line. Biomed Res. Int. 2014; 2014:365867.

Jiang J, Tang YL, Liang XH. EMT: A new vision of hypoxia promoting cancer progression. Cancer Biol. Ther. 2011; 11:714-23.

Jiang L, Luo RY, Yang J and Cheng YX. Knockdown of survivin contributes to antitumor activity in cisplatin-resistant ovarian cancer cells. Mol Med Rep. 2013; 7:425-430.

Jiao M and Nan K. Activation of PI3 kinase/Akt/HIF-1 pathway contributes to hypoxia-induced epithelial-mesenchymal transition and chemoresistance in hepatocellular carcinoma. Int. J. 
Oncol. 2012; 40:461-468.

Jose C, Bellance N, Rossignol R. Choosing between glycolysis and oxidative phosphorylation: a tumor's dilemma? Biochim. Biophys. Acta. 2011; 1807:552-61.

Ju T, Lanneau GS, Gautam T, Wang Y, Xia B, Stowell SR, Willard MT, Wang W, Xia JY, Zuna RE, Laszik Z, Benbrook DM, Hanigan MH, Cummings RD. Human tumor antigens Tn and sialyl Tn arise from mutations in Cosmc. Cancer Res. 2008; 68:1636-46.

Julien S, Adriaenssens E, Ottenberg K, Furlan A, Courtand G, Vercoutter-Edouart AS, Hanisch FG, Delannoy P, and Le Bourhis X. ST6GalNAc I expression in MDA-MB-231 breast cancer cells greatly modifies their O-glycosylation pattern and enhances their tumourigenicity. Glycobiology. 2006; 16:54-64.

Julien S, Ivetic A, Grigoriadis A, QiZe D, Burford B, Sproviero D, Picco G, Gillett C, Papp SL, Schaffer L, Tutt A, Taylor-Papadimitriou J, Pinder SE, and Burchell JM. Selectin ligand sialyl-lewis $\mathrm{x}$ antigen drives metastasis of hormone-dependent breast cancers. Cancer Res. 2011; 71:7683-93.

Julien S, Videira PA and Delannoy P, 2012. Sialyl-tn in cancer: (how) did we miss the target? Biomolecules. 2012; 2:435-66.

Kamal A, Faazil S, Malik MS. Apoptosis-inducing agents: a patent review (2010 - 2013). Expert Opin Ther Pat. 2014; 24:339-54.

Kamaraj S, Anandakumar P, Jagan S, Ramakrishnan G, Devaki T. Modulatory effect of hesperidin on benzo(a)pyrene induced experimental lung carcinogenesis with reference to COX-2, MMP-2 and MMP-9. Eur. J. Pharmacol. 2010; 649:320-7.

Kannagi R. Carbohydrate Antigen Sialyl Lewis a - Its Pathophysiological Significance and Induction Mechanism in Cancer Progression. Chang Gung Med J. 2007; 30:189-209.

Kannagi R. Carbohydrate-mediated cell adhesion involved in hematogenous metastasis of cancer. Glycoconj J. 1997; 14:577-84.

Karasawa $\mathrm{T}$ and Steyger PS. An integrated view of cisplatin-induced nephrotoxicity and ototoxicity. Toxicol Lett. 2015; 237:219-227.

Karran P, Offman J, Bignami M. Human mismatch repair, drug-induced DNA damage, and secondary cancer. Biochimie. 2003; 85:1149-60.

Karsten U and Goletz S. What makes cancer stem cell markers different? Springerplus. 2013; 2:301.

Kato J, Kuwabara Y, Mitani M, Shinoda N, Sato A, Toyama T, Mitsui A, Nishiwaki T, Moriyama S, Kudo J, Fujii.Y. Expression of survivin in esophageal cancer: correlation with the prognosis and response to chemotherapy. Int J Cancer. 2001; 95:92-95.

Kelland L. The resurgence of platinum-based cancer chemotherapy. Nat Rev Cancer. 2007; 7:573-84.

Keppler D. Export pumps for glutathione S-conjugates. Free Radic Biol Med. 1999; 27:985-91.

Khaldoyanidi SK, Glinsky VV, Sikora L, Glinskii AB, Mossine VV, Quinn TP, Glinsky GV, 
and Sriramarao P. MDA-MB-435 human breast carcinoma cell homo- and heterotypic adhesion under flow conditions is mediated in part by Thomsen-Friedenreich antigengalectin-3 interactions. J Biol Chem. 2003; 278:4127-34.

Kim C, Kasuya J, Jeon J, Chung S, Kamm RD. A quantitative microfluidic angiogenesis screen for studying anti-angiogenic therapeutic drugs. Lab Chip. 2015; 15:301-10.

Kim DH, Oh SJ, Oh CA, Choi MG, Noh JH, Sohn TS, Bae JM, and Kim S. The relationships between perioperative CEA, CA 19-9, and CA 72-4 and recurrence in gastric cancer patients after curative radical gastrectomy. J Surg Oncol. 2011; 104:585-91.

Kim HR, Lin HM, Biliran H, and Raz A. Cell cycle arrest and inhibition of anoikis by galectin3 in human breast epithelial cells. Cancer Res. 1999; 59:4148-54.

Kim SS, Rait A, Kim E, Pirollo KF, Nishida M, Farkas N, Dagata JA, and Chang EH. A nanoparticle carrying the p53 gene targets tumors including cancer stem cells, sensitizes glioblastoma to chemotherapy and improves survival. ACS Nano. 2014; 8:5494-514.

Kirschner K and Melton DW. Multiple roles of the ERCC1-XPF endonuclease in DNA repair and resistance to anticancer drugs. Anticancer Res. 2010; 30:3223-32.

Knipp M. Metallothioneins and Platinum(II) Anti-Tumor Compounds. Curr Med Chem. 2009; 16:522-537.

Kohane IS. HEALTH CARE POLICY. Ten things we have to do to achieve precision medicine. Science. 2015; 349:37-8.

Konkimalla VB, Kaina B, Efferth T. Role of transporter genes in cisplatin resistance. In Vivo (Brooklyn). 2008; 22:279-284.

Korita PV, Wakai T, Shirai Y, Matsuda Y, Sakata J, Takamura M, Yano M, Sanpei A, Aoyagi Y, Hatakeyama K, Ajioka Y. Multidrug resistance-associated protein 2 determines the efficacy of cisplatin in patients with hepatocellular carcinoma. Oncol. Rep. 2010; 23:96572.

Kouniavsky G, Khaikin M, Zvibel I, Zippel D, Brill S, Halpern Z, Papa M. Stromal extracellular matrix reduces chemotherapy-induced apoptosis in colon cancer cell lines. Clin. Exp. Metastasis. 2002; 19:55-60.

Kramer R, Weber TK, Arceci R, Ramchurren N, Kastrinakis WV, Steele G Jr, and Summerhayes IC. Inhibition of N-linked glycosylation of P-glycoprotein by tunicamycin results in a reduced multidrug resistance phenotype. Br J Cancer. 1995; 71:670-5.

Kudo T, Nakagawa H, Takahashi M, Hamaguchi J, Kamiyama N, Yokoo H, Nakanishi K, Nakagawa T, Kamiyama T, Deguchi K, Nishimura S, and Todo S. N-glycan alterations are associated with drug resistance in human hepatocellular carcinoma. Mol Cancer. 2007; $6: 32$.

Kulkarni AA, Weiss AA, Iyer SS. Glycan-based high-affinity ligands for toxins and pathogen receptors. Med Res Rev. 2010; 30:327-93.

Kwa M, Edwards S, Downey A, Reich E, Wallach R, Curtin J, Muggia F. Ovarian cancer in BRCA mutation carriers: improved outcome after intraperitoneal (IP) cisplatin. Ann Surg 
Oncol. 2014; 21:1468-73.

Kwon HC, Roh MS, Oh SY, Kim SH, Kim MC, Kim JS, Kim HJ. Prognostic value of expression of ERCC1, thymidylate synthase, and glutathione S-transferase P1 for 5fluorouracil/oxaliplatin chemotherapy in advanced gastric cancer. Ann Oncol. 2007; 18:504-9.

Lai Y, Yip GW, Bay BH. Targeting metallothionein for prognosis and treatment of breast cancer. Recent Pat Anticancer Drug Discov. 2011; 6:178-85.

Lajoie P, Goetz JG, Dennis JW, and Nabi IR. Lattices, rafts, and scaffolds: domain regulation of receptor signaling at the plasma membrane. J Cell Biol. 2009; 185:381-5.

Lakshminarayan R, Wunder C, Becken U, Howes MT, Benzing C, Arumugam S, Sales S, Ariotti N, Chambon V, Lamaze C, Loew D, Shevchenko A, Gaus K, Parton RG, Johannes L. Galectin-3 drives glycosphingolipid-dependent biogenesis of clathrin-independent carriers. Nat Cell Biol. 2014; 16:595-606.

Lakshminarayanan V, Thompson P, Wolfert MA, Buskas T, Bradley JM, Pathangey LB, Madsen CS, Cohen PA, Gendler SJ, and Boons GJ. Immune recognition of tumorassociated mucin MUC1 is achieved by a fully synthetic aberrantly glycosylated MUC1 tripartite vaccine. Proc Natl Acad Sci U S A. 2012; 109:261-6.

Langan RC, Mullinax JE, Raiji MT, Upham T, Summers T, Stojadinovic A, Avital I. Colorectal cancer biomarkers and the potential role of cancer stem cells. J Cancer. 2013; 4:241-50.

Lau KS and Dennis JW. N-Glycans in cancer progression. Glycobiology. 2008; 18:750-60.

Lazar IM, Lazar AC, Cortes DF, and Kabulski JL. Recent advances in the MS analysis of glycoproteins: Theoretical considerations. Electrophoresis. 2011; 32:3-13.

Lee MM, Nasirikenari M, Manhardt CT, Ashline DJ, Hanneman AJ, Reinhold VN, and Lau JT. Platelets support extracellular sialylation by supplying the sugar donor substrate. J Biol Chem. 2014; 289:8742-8.

Leong CO, Vidnovic N, DeYoung MP, Sgroi D, Ellisen LW. The p63/p73 network mediates chemosensitivity to cisplatin in a biologically defined subset of primary breast cancers. $\mathrm{J}$ Clin Invest. 2007; 117:1370-80.

Leung EL, Fiscus RR, Tung JW, Tin VP, Cheng LC, Sihoe AD, Fink LM, Ma Y, Wong MP. Non-small cell lung cancer cells expressing CD44 are enriched for stem cell-like properties. PLoS One. 2010; 5:e14062.

Levina V, Marrangoni AM, DeMarco R, Gorelik E, and Lokshin AE. Drug-selected human lung cancer stem cells: Cytokine network, tumorigenic and metastatic properties. PLoS One. 2008; 3:e3077.

Li D, Zhang Y, Xie Y, Xiang J, Zhu Y, Yang J. Enhanced tumor suppression by adenoviral PTEN gene therapy combined with cisplatin chemotherapy in small-cell lung cancer. Cancer Gene Ther. 2013; 20:251-9.

Li L, Cole J, Margolin DA. Cancer stem cell and stromal microenvironment. Ochsner J. 2013; 13:109-18. 
Li Q and Shu Y. Role of solute carriers in response to anticancer drugs. Mol. Cell. Ther. 2014; 2:15.

Li R, Zang Y, Li C, Patel NS, Grandis JR, and Johnson DE. ABT-737 synergizes with chemotherapy to kill head and neck squamous cell carcinoma cells via a Noxa-mediated pathway. Mol Pharmacol. 2009; 75:1231-9.

Li ZH, Qiu MZ, Zeng ZL, Luo HY, Wu WJ, Wang F, Wang ZQ, Zhang DS, Li YH, Xu RH. Copper-transporting P-type adenosine triphosphatase (ATP7A) is associated with platinum-resistance in non-small cell lung cancer (NSCLC). J Transl Med. 2012; 10:21.

Liang X, Guo Y, Figg WD, Fojo AT, Mueller MD, Yu JJ. The Role of Wild-Type p53 in Cisplatin-Induced Chk2 Phosphorylation and the Inhibition of Platinum Resistance with a Chk2 Inhibitor. Chemother Res Pr. 2011; 2011:715469.

Liang ZD, Long Y, Chen HHW, Savaraj N, Kuo MT. Regulation of the high-affinity copper transporter (hCtr1) expression by cisplatin and heavy metals. J Biol Inorg Chem. 2014; 19:17-27.

Liang ZD, Long Y, Tsai W, Fu S, Kurzrock R, Gagea-lurascu M, Zhang F, Chen HHW, Hennessy BT, Mills GB, Savaraj N, and Kuo MT. Mechanistic Basis for Overcoming Platinum Resistance Using Copper Chelating Agents. Mol Cancer Ther. 2012; 11:248394.

Liao CP, Adisetiyo H, Liang M, Roy-Burman P. Cancer-associated Fibroblasts Enhance GlanForming Capability of Prostate Cancer Stem Cells. Cancer Res. 2010; 70:7294-303.

Lima L, Severino PF, Silva M, Miranda A, Tavares A, Pereira S, Fernandes E, Cruz R, Amaro T, Reis CA, Dall'Olio F, Amado F, Videira PA, Santos L, Ferreira JA. Response of highrisk of recurrence/progression bladder tumours expressing sialyl-Tn and sialyl-6-T to BCG immunotherapy. Br J Cancer. 2013; 109:2106-14.

Lin Q and Yun Z. Impact of the hypoxic tumor microenvironment on the regulation of cancer stem cell characteristics. Cancer Biol. Ther. 2010; 9:949-56.

Lin W, Karsten U, Goletz S, Cheng RC, and Cao Y. Expression of CD176 (ThomsenFriedenreich antigen) on lung, breast and liver cancer-initiating cells. Int J Exp Pathol. 2011; 92:97-105.

Liu FT and Rabinovich GA. Galectins as modulators of tumour progression. Nat Rev Cancer. 2005; 5:29-41.

Liu H, Wu Q, Liu Y, Liu W, Zhang W, Pan D, Xu J. Prognostic significance of $\beta 1,6-N-$ acetylglucosaminyltransferase $\mathrm{V}$ expression in patients with hepatocellular carcinoma. Jpn J Clin Oncol. 2015; 45:844-53.

Liu P, Zhu Y, and Liu L. Elevated serum CA72-4 levels predict poor prognosis in pancreatic adenocarcinoma after intensity-modulated radiation therapy. Oncotarget. 2015; 6:9592-9.

Liu R, Li H, Liu L, Yu J, Ren X. Fibroblast activation protein: A potential therapeutic target in cancer. Cancer Biol Ther. 2012; 13:123-9.

Livney YD and Assaraf YG. Rationally designed nanovehicles to overcome cancer 
chemoresistance. Adv Drug Deliv Rev. 2013; 65:1716-30.

Lockhart AC, Tirona RG, Kim RB. Pharmacogenetics of ATP-binding cassette transporters in cancer and chemotherapy. Mol. Cancer Ther. 2003; 2:685-98.

Loeffler M, Krüger JA, Niethammer AG, and Reisfeld RA. Targeting tumor-associated fibroblasts improves cancer chemotherapy by increasing intratumoral drug uptake. J. Clin. Invest. 2006; 116;1955-62.

Lotti F, Jarrar AM, Pai RK, Hitomi M, Lathia J, Mace A, Gantt GA Jr, Sukhdeo K, DeVecchio J, Vasanji A, Leahy P, Hjelmeland AB, Kalady MF, Rich JN. Chemotherapy activates cancer-associated fibroblasts to maintain colorectal cancer-initiating cells by IL-17A. J Exp Med. 2013; 210:2851-72.

Louhimo J, Alfthan H, Stenman UH, Haglund C. Serum HCG beta and CA 72-4 are stronger prognostic factors than CEA, CA 19-9 and CA 242 in pancreatic cancer. Oncology. 2004; 66:126-31.

Louhimo J, Kokkola A, Alfthan H, Stenman UH, Haglund C. Preoperative hCGbeta and CA 724 are prognostic factors in gastric cancer. Int J Cancer. 2004; 111:929-33.

Mahadevan D and Von Hoff DD. Tumor-stroma interactions in pancreatic ductal adenocarcinoma. Mol. Cancer Ther. 2007; 6:1186-97.

Marcel V, Petit I, Murray-Zmijewski F, Goullet de Rugy T, Fernandes K, Meuray V, Diot A, Lane DP, Aberdam D, and Bourdon JC. Diverse p63 and p73 isoforms regulate $\Delta 133 \mathrm{p} 53$ expression through modulation of the internal TP53 promoter activity. Cell Death Differ. $2012 ; 19: 816-26$.

Marcos NT, Bennett EP, Gomes J, Magalhaes A, Gomes C, David L, Dar I, Jeanneau C, DeFrees S, Krustrup D, Vogel LK, Kure EH, Burchell J, Taylor-Papadimitriou J, Clausen H, Mandel U, Reis CA. ST6GalNAc-I controls expression of sialyl-Tn antigen in gastrointestinal tissues. Front Biosci (Elite Ed). 2011; 3:1443-55.

Marcos NT, Pinho S, Grandela C, Cruz A, Samyn-Petit B, Harduin-Lepers A, Almeida R, Silva F, Morais V, Costa J, Kihlberg J, Clausen H, Reis CA. Role of the human ST6GalNAc-I and ST6GalNAc-II in the synthesis of the cancer-associated sialyl-Tn antigen. Cancer Res. 2004; 64:7050-7.

Margeli M, Cirauqui B, Castella E, Tapia G, Costa C, Gimenez-Capitan A, Barnadas A, Sanchez Ronco M, Benlloch S, Taron M, Rosell R. The prognostic value of BRCA1 mRNA expression levels following neoadjuvant chemotherapy in breast cancer. PLoS One. 2010; 5:e9499.

Martin LP, Hamilton TC, Schilder RJ. Platinum resistance: The role of DNA repair pathways. Clin Cancer Res. 2008; 14:1291-95.

Materna V, Liedert B, Thomale J, Lage H. Protection of platinum-DNA adduct formation and reversal of cisplatin resistance by anti-MRP2 hammerhead ribozymes in human cancer cells. Int J Cancer. 2005; 115:393-402.

Mathews LA, Cabarcas SM, Farrar WL. DNA repair: The culprit for tumor-initiating cell survival? Cancer Metastasis Rev.2011; 30:185-97. 
Matsui T, Kojima H, Suzuki H, Hamajima H, Nakazato H, Ito K, Nakao A, and Sakamoto J. Sialyl Lewis a expression as a predictor of the prognosis of colon carcinoma patients in a prospective randomized clinical trial. Jpn J Clin Oncol. 2004; 34:588-93.

Maugeri-Saccà M, Bartucci M, and De Maria R. DNA Damage Repair Pathways in Cancer Stem Cells. Mol Cancer Ther. 2012;11:1627-36.

Mazzoni F, Cecere FL, Meoni G, Giuliani C, Boni L, Camerini A, Lucchesi S, Martella F, Amoroso D, Lucherini E, Torricelli F, Di Costanzo F. Phase II trial of customized first line chemotherapy according to ERCC1 and RRM1 SNPs in patients with advanced non-smallcell lung cancer. Lung Cancer. 2013; 82:288-93.

McNeil EM and Melton DW. DNA repair endonuclease ERCC1-XPF as a novel therapeutic target to overcome chemoresistance in cancer therapy. Nucleic Acids Res. 2012; 40:999010004 .

Medina V, Calvo MB, Díaz-Prado S, Espada J. Hedgehog signalling as a target in cancer stem cells. Clin. Transl. Oncol. 2009; 11:199-207.

Meistrich ML. Male Gonadal Toxicity. Pediatr Blood Cancer. 2009; 53:261-66.

Michaud WA, Nichols AC, Mroz EA, Faquin WC, Clark JR, Begum S, Westra WH, Wada H, Busse PM, Ellisen LW, and Rocco JW. Bcl-2 blocks cisplatin-induced apoptosis and predicts poor outcome following chemoradiation treatment in advanced oropharyngeal squamous cell carcinoma. Clin Cancer Res. 2009; 15:1645-54.

Minchinton AI and Tannock IF. Drug penetration in solid tumours. Nat. Rev. Cancer. 2006; 6:583-92.

Mintz MB, Sowers R, Brown KM, Hilmer SC, Mazza B, Huvos AG, Meyers PA, LaFleur B, McDonough WS, Henry MM, Ramsey KE, Antonescu CR, Chen W, Healey JH, Daluski A, Berens ME, MacDonald TB, Gorlick R, Stephan DA. An expression signature classifies chemotherapy-resistant pediatric osteosarcoma. Cancer Res. 2005; 65:1748-54.

Miyamoto H, Murakami T, Tsuchida K, Sugino H, Miyake H, Tashiro S. Tumor-stroma interaction of human pancreatic cancer: acquired resistance to anticancer drugs and proliferation regulation is dependent on extracellular matrix proteins. Pancreas. 2004; 28:38-44.

Mucaj V, Shay JES, Simon MC. Effects of hypoxia and HIFs on cancer metabolism. Int. J. Hematol. 2012; 95:464-70.

Mullan PB, Quinn JE and Harkin DP. The role of BRCA1 in transcriptional regulation and cell cycle control. Oncogene. 2006; 25:5854-63.

Müller M, Schilling T, Sayan AE, Kairat A, Lorenz K, Schulze-Bergkamen H, Oren M, Koch A, Tannapfel A, Stremmel W, Melino G, and Krammer PH. TAp73/Delta Np73 influences apoptotic response, chemosensitivity and prognosis in hepatocellular carcinoma. Cell Death Differ. 2005; 12:1564-77.

Müller M, Schleithoff ES, Stremmel W, Melino G, Krammer PH, Schilling T. One, two, threep53, p63, p73 and chemosensitivity. Drug Resist Updat. 2006; 9:288-306. 
Muniandy PA, Liu J, Majumdar A, Liu ST, Seidman MM. DNA Interstrand Crossling Repair in Mammalian Cells: Step by Step. Crit Rev Biochem Mol Biol. 2010; 45:23-49.

Muñoz P, Iliou MS, Esteller M. Epigenetic alterations involved in cancer stem cell reprogramming. Mol. Oncol. 2012; 6:620-36.

Muris JJ, Cillessen SA, Vos W, van Houdt IS, Kummer JA, van Krieken JH, Jiwa NM, Jansen PM, Kluin-Nelemans HC, Ossenkoppele GJ, Gundy C, Meijer CJ, and Oudejans JJ. Immunohistochemical profiling of caspase signaling pathways predicts clinical response to chemotherapy in primary nodal diffuse large B-cell lymphomas. Blood. 2005; 105:291623 .

Muthana SM, Campbell CT, and Gildersleeve JC. Modifications of glycans: biological significance and therapeutic opportunities. ACS Chem Biol. 2012; 7:31-43.

Nadal R and Bellmunt J. New Treatments for Bladder Cancer: When Will We Make Progress? Curr Treat Options Oncol. 2014; 15:99-114.

Nagase H, Visse R, Murphy G. Structure and function of matrix metalloproteinases and TIMPs. Cardiovasc Res. 2006; 69:562-73.

Nakagawa H, Wakabayashi-Nakao K, Tamura A, Toyoda Y, Koshiba S and Ishikawa T. Disruption of $\mathrm{N}$-linked glycosylation enhances ubiquitin-mediated proteasomal degradation of the human ATP-binding cassette transporter ABCG2. FEBS J. 2009; 276:7237-52.

Nangia-Makker P, Balan V, Raz A. Regulation of tumor progression by extracellular galectin-3. Cancer Microenviron. 2008; 1:43-51.

Nangia-Makker P, Wang Y, Raz T, Tait L, Balan V, Hogan V, and Raz A. Cleavage of galectin3 by matrix metalloproteases induces angiogenesis in breast cancer. Int $\mathrm{J}$ Cancer. 2010; 127:2530-41.

Nasirikenari M, Veillon L, Collins CC, Azadi P, and Lau JT. Remodeling of marrow hematopoietic stem and progenitor cells by non-self ST6Gal-1 sialyltransferase. J Biol Chem. 2014; 289:7178-89.

Nath S and Mukherjee P. MUC1: a multifaceted oncoprotein with a key role in cancer progression. Trends Mol Med. 2014; 20:332-42.

Navarro G, Sawant RR, Biswas S, Essex S, Tros de Ilarduya C, and Torchilin VP. Pglycoprotein silencing with siRNA delivered by DOPE-modified PEI overcomes doxorubicin resistance in breast cancer cells. Nanomedicine (Lond). 2012; 7:65-78.

Noda I, Fujieda S, Seki M, Tanaka N, Sunaga H, Ohtsubo T, Tsuzuki H, Fan GK, Saito H. Inhibition of $\mathrm{N}$-linked glycosylation by tunicamycin enhances sensitivity to cisplatin in human head-and-neck carcinoma cells. Int J Cancer. 1999; 80:279-84.

Ohashi R, Takahashi F, Cui R, Yoshioka M, Gu T, Sasaki S, Tominaga S, Nishio K, Tanabe $\mathrm{KK}$, Takahashi K. Interaction between CD44 and hyaluronate induces chemoresistance in non-small cell lung cancer cell. Cancer Lett. 2007; 252:225-34.

Ohtsubo K and Marth JD, 2006. Glycosylation in Cellular Mechanisms of Health and Disease. 
Cell. 2006; 126:855-67.

Okuno S, Sato H, Tamba M, Wang H, Sohda S, Hamada H, Yoshikawa H. Role of cystine transport in intracellular glutathione level and cisplatin resistance in human ovarian cancer cell lines. Br J Cancer. 2003; 88:951-6.

Palorini R, Cammarata FP, Balestrieri C, Monestiroli A, Vasso M, Gelfi C, Alberghina L, and Chiaradonna F. Glucose starvation induces cell death in K-ras-transformed cells by interfering with the hexosamine biosynthesis pathway and activating the unfolded protein response. Cell Death Dis. 2013; 4:e732.

Park $\mathrm{J}$ and Lee $\mathrm{M}$. Increasing the $\alpha$ 2, 6 sialylation of glycoproteins may contribute to metastatic spread and therapeutic resistance in colorectal cancer. Gut Liver. 2013; 7:629-41.

Park JM, Huang S, Tougeron D, Sinicrope FA. MSH3 Mismatch Repair Protein Regulates Sensitivity to Cytotoxic Drugs and a Histone Deacetylase Inhibitor in Human Colon Carcinoma Cells. PLoS One. 2013; 8:e65369.

Park MS, De Leon M, and Devarajan P. Cisplatin induces apoptosis in LLC-PK1 cells via activation of mitochondrial pathways. J Am Soc Nephrol. 2002; 13:858-65.

Pawlowski J and Kraft AS. Bax-induced apoptotic cell death. Proc Natl Acad Sci U S A. 2000; 97:529-31.

Peklak-Scott C, Smitherman PK, Townsend AJ, and Morrow CS. Role of glutathione Stransferase P1-1 in the cellular detoxification of cisplatin. Mol Cancer Ther. 2008; 7:324755 .

Peng B, Gu Y, Xiong Y, Zheng G, He Z. Microarray-assisted pathway analysis identifies MT1X \& NFKB as mediators of TCRP1-associated resistance to cisplatin in oral squamous cell carcinoma. PLoS One. 2012; 7:e51413.

Peng $G$ and Lin SY. Exploiting the homologous recombination DNA repair network for targeted cancer therapy. World J Clin Oncol. 2011; 2:73-9.

Peng W, Wang HY, Miyahara Y, Peng G, and Wang RF. Tumor-associated galectin-3 modulates the function of tumor-reactive T cells. Cancer Res. 2008; 68:7228-36.

Petris MJ, Smith K, Lee J, Thiele DJ. Copper-stimulated endocytosis and degradation of the human copper transporter, hCtr1. J. Biol. Chem. 2003; 278:9639-46.

Pietras K and Östman A. Hallmarks of cancer: Interactions with the tumor stroma. Exp. Cell Res. 2010; 316:1324-31.

Pinho S, Marcos NT, Ferreira B, Carvalho AS, Oliveira MJ, Santos-Silva F, Harduin-Lepers A, Reis CA. Biological significance of cancer-associated sialyl-Tn antigen: modulation of malignant phenotype in gastric carcinoma cells. Cancer Lett. 2007; 249:157-70.

Pinho SS and Reis CA. Glycosylation in cancer: mechanisms and clinical implications. Nat Rev Cancer. 2015; 15:540-55.

Pinho SS, Figueiredo J, Cabral J, Carvalho S, Dourado J, Magalhães A, Gärtner F, Mendonfa AM, Isaji T, Gu J, Carneiro F, Seruca R, Taniguchi N, Reis CA. E-cadherin and adherensjunctions stability in gastric carcinoma: functional implications of glycosyltransferases 
involving $\mathrm{N}$-glycan branching biosynthesis, $\mathrm{N}$-acetylglucosaminyltransferases III and V. Biochim Biophys Acta. 2013; 1830:2690-700.

Pinho SS, Oliveira P, Cabral J, Carvalho S, Huntsman D, Gärtner F, Seruca R, Reis CA, Oliveira C. Loss and recovery of Mgat3 and GnT-III mediated E-cadherin N-glycosylation is a mechanism involved in epithelial-Mesenchymal-Epithelial transitions. PLoS One. 2012; 7:e33191.

Pinho SS, Seruca R, Gärtner F, Yamaguchi Y, Gu J, Taniguchi N, Reis CA. Modulation of Ecadherin function and dysfunction by N-glycosylation. Cell Mol Life Sci. 2011; 68:101120.

Pisano C, Vlodavsky I, Ilan N, Zunino F. The potential of heparanase as a therapeutic target in cancer. Biochem Pharmacol. 2014; 89:12-9.

Pistolesi S, Nuti M, Castagna M, Pingitore R. Mammary fetal gland: identification of new oncofetal antigens by monoclonal antibodies B72.3, MM1.80 and 4.36. Tumori. 2001; $87: 252-5$.

Plasilova M, Zivny J, Jelinek J, Neuwirtova R, Cermak J, Necas E, Andera L, and Stopka T. TRAIL (Apo2L) suppresses growth of primary human leukemia and myelodysplasia progenitors. Leukemia. 2002; 16:67-73.

Polyak K and Weinberg RA. Transitions between epithelial and mesenchymal states: acquisition of malignant and stem cell traits. Nat. Rev. Cancer. 2009; 9:265-73.

Pommier Y, Sordet O, Antony S, Hayward RL and Kohn KW. Apoptosis defects and chemotherapy resistance: molecular interaction maps and networks. Oncogene. 2004; 23:2934-49.

Portela SV, Martín CV, Romay LM, Cuevas E, Martín EG, and Briera AF. sLea and sLex expression in colorectal cancer: implications for tumourigenesis and disease prognosis. Histol Histopathol. 2011; 26:1305-16.

Puré E. The road to integrative cancer therapies: emergence of a tumor-associated fibroblast protease as a potential therapeutic target in cancer. Expert Opin Ther Targets. 2009; 13:957-73.

Qian W, Wang J, Roginskaya V, McDermott LA, Edwards RP, Stolz DB, Llambi F, Green DR, Van Houten B. Novel combination of mitochondrial division inhibitor 1 (mdivi-1) and platinum agents produces synergistic pro-apoptotic effect in drug resistant tumor cells. Oncotarget. 2014; 5:4180-94.

QingShuo M, Qi Y, and YaPing Li. Nanocarriers for siRNA delivery to overcome cancer multidrug resistance. Chin Sci Bull. 2013; 58:4021-30.

Quinn JE, James CR, Stewart GE, Mulligan JM, White P, Chang GK, Mullan PB, Johnston PG, Wilson RH, Harkin DP. BRCA1 mRNA expression levels predict for overall survival in ovarian cancer after chemotherapy. Clin Cancer Res. 2007; 13:7413-20.

Rabinovich GA and Toscano MA. Turning "sweet" on immunity: galectin-glycan interactions in immune tolerance and inflammation. Nat Rev Immunol. 2009; 9:338-52. 
Radhakrishnan P, Dabelsteen S, Madsen FB, Francavilla C, Kopp KL, Steentoft C, Vakhrushev SY, Olsen JV, Hansen L, Bennett EP, Woetmann A, Yin G, Chen L, Song H, Bak M, Hlady RA, Peters SL, Opavsky R, Thode C, Qvortrup K, Schjoldager KT, Clausen H, Hollingsworth MA, Wandall HH. Immature truncated O-glycophenotype of cancer directly induces oncogenic features. Proc Natl Acad Sci U S A. 2014; 111:E4066-75.

Raguz S and Yague E. Resistance to chemotherapy: new treatments and novel insights into an old problem. Br. J. Cancer. 2008; 99:387-91.

Ravi R, Jain AJ, Schulick RD, Pham V, Prouser TS, Allen H, Mayer EG, Yu H, Pardoll DM, Ashkenazi A, Bedi A. Elimination of hepatic metastases of colon cancer cells via p53independent cross- talk between irinotecan and Apo2 ligand/TRAIL. Cancer Res. 2004; 64:9105-14.

Reis CA, Osorio H, Silva L, Gomes C, David L. Alterations in glycosylation as biomarkers for cancer detection. J Clin Pathol. 2010; 63:322-9.

Reticker-Flynn NE, Bhatia SN. Aberrant glycosylation promotes lung cancer metastasis through adhesion to galectins in the metastatic niche. Cancer Discov. 2015; 5:168-81.

Rocco JW, Leong CO, Kuperwasser N, DeYoung MP, Ellisen LW. p63 mediates survival in squamous cell carcinoma by suppression of p73-dependent apoptosis. Cancer Cell. 2006; 9:45-56.

Rocha CR, Garcia CC, Vieira DB, Quinet A, de Andrade-Lima LC, Munford V, Belizário JE, Menck CF. Glutathione depletion sensitizes cisplatin- and temozolomide-resistant glioma cells in vitro and in vivo. Cell Death Dis. 2014; 5:e1505.

Rodriguez FO, Palou-Redorta J, Fernández-Gómez JM, Algaba F, Eiró N, Villavicencio H, and Vizoso FJ. Matrix Metalloproteinases and Bladder Cancer: What is New? ISRN Urol. 2012; 2012:581539.

Rohwer N, Cramer T. Hypoxia-mediated drug resistance: novel insights on the functional interaction of HIFs and cell death pathways. Drug Resist Updat. 2011; 14:191-201.

Rong G, Kang H, Wang Y, Hai T, Sun H. Candidate Markers That Associate with Chemotherapy Resistance in Breast Cancer through the Study on Taxotere-Induced Damage to Tumor Microenvironment and Gene Expression Profiling of CarcinomaAssociated Fibroblasts (CAFs). PLoS One. 2013; 8:e70960.

Rosenberg B. Platinum Coordination Complexes in Cancer Chemotherapy. Naturwissenschaften. 1973; 60:399-406.

Ruan K, Song G, and Ouyang G. Role of hypoxia in the hallmarks of human cancer. J Cell Biochem. 2009; 107:1053-62.

Ruppen J, Cortes-Dericks L, Marconi E, Karoubi G, Schmid RA, Peng R, Marti TM, Guenat OT. A microfluidic platform for chemoresistive testing of multicellular pleural cancer spheroids. Lab Chip. 2014; 14:1198-205.

Safaei R, Otani S, Larson BJ, Rasmussen ML, Howell SB. Transport of cisplatin by the copper efflux transporter ATP7B. Mol. Pharmacol. 2008; 73:461-8. 
Sawers L, Ferguson MJ, Ihrig BR, Young HC, Chakravarty P, Wolf CR, Smith G. Glutathione S-transferase P1 (GSTP1) directly influences platinum drug chemosensitivity in ovarian tumour cell lines. Br J Cancer. 2014; 111:1150-8.

Schjoldager KT and Clausen H. Site-specific protein O-glycosylation modulates proprotein processing - deciphering specific functions of the large polypeptide GalNAc-transferase gene family. Biochim Biophys Acta. 2012; 1820:2079-94.

Scholten DJ, Timmer CM, Peacock JD, Pelle DW, Williams BO, Steensma MR. Down Regulation of Wnt Signaling Mitigates Hypoxia-Induced Chemoresistance in Human Osteosarcoma Cells. PLoS One. 2014; 9:e111431.

Schultz MJ, Swindall AF, Wright JW, Sztul ES, Landen CN, and Bellis SL. ST6Gal-I sialyltransferase confers cisplatin resistance in ovarian tumor cells. J Ovarian Res. 2013; $6: 25$.

Semenza GL. HIF-1, O(2), and the 3 PHDs: how animal cells signal hypoxia to the nucleus. Cell. 2001; 107:1-3.

Sethi T, Rintoul RC, Moore SM, MacKinnon AC, Salter D, Choo C, Chilvers ER, Dransfield I, Donnelly SC, Strieter R, Haslett C. Extracellular matrix proteins protect small cell lung cancer cells against apoptosis: A mechanism for small cell lung cancer growth and drug resistance in vivo. Nat. Med. 1999; 5:662-8.

Shah NP. BRCA: from therapeutic target to therapeutic shield. Nat. Med. 2008; 14:495-6.

Shannon AM, Bouchier-Hayes DJ, Condron CM and Toomey D. Tumour hypoxia, chemotherapeutic resistance and hypoxia-related therapies. Cancer Treat. Rev. 2003; 29:297-307.

Shapira A, Livney YD, Broxterman HJ, Assaraf YG. Nanomedicine for targeted cancer therapy: Towards the overcoming of drug resistance. Drug Resist Updat. 2011; 14:150-63.

Shen D, Pouliot LM, Hall MD, and Gottesman MM. Cisplatin resistance: a cellular self-defense mechanism resulting from multiple epigenetic and genetic changes. Pharmacol. Rev. 2012; 64:706-21.

Shental-Bechor D, Levy Y. Folding of glycoproteins: toward understanding the biophysics of the glycosylation code. Curr Opin Struct Biol. 2009; 19:524-33.

Sherman-Baust CA, Becker KG, Wood WH, Zhang Y and Morin PJ. Gene expression and pathway analysis of ovarian cancer cells selected for resistance to cisplatin, paclitaxel, or doxorubicin. J. Ovarian Res. 2011; 4:21.

Sherman-Baust CA, Weeraratna AT, Rangel LB, Pizer ES, Cho KR, Schwartz DR, Shock T, Morin PJ. Remodeling of the extracellular matrix through overexpression of collagen VI contributes to cisplatin resistance in ovarian cancer cells. Cancer Cell. 2003; 3:377-86.

Shirato K, Nakajima K, Korekane H, Takamatsu S, Gao C, Angata T, Ohtsubo K, and Taniguchi N. Hypoxic regulation of glycosylation via the $\mathrm{N}$ acetylglucosamine cycle. J. Clin. Biochem. Nutr. 2011; 48:20-5.

Siddik ZH. Cisplatin: mode of cytotoxic action and molecular basis of resistance. Oncogene. 
$2003 ; 22: 7265-79$.

Signore M, Ricci-Vitiani L, De Maria R. Targeting apoptosis pathways in cancer stem cells. Cancer Lett. 2013; 332:374-82.

Singh R, Campbell BJ, Yu LG, Fernig DG, Milton JD, Goodlad RA, FitzGerald AJ, and Rhodes JM. Cell surface-expressed Thomsen-Friedenreich antigen in colon cancer is predominantly carried on high molecular weight splice variants of CD44. Glycobiology. 2001; 11:587-92.

Siu LL, Banerjee D, Khurana RJ, Pan X, Pflueger R, Tannock IF, Moore MJ. The Prognostic Carcinoma Role of p53, Metallothionein, P-glycoprotein, and MIB-1 in Muscle-invasive Urothelial Transitional Cell Carcinoma. Clin. cancer Res. 1998; 4:559-65.

Song Y, Zhou X, Bai W, Ma X. FBW7 increases drug sensitivity to cisplatin in human nasopharyngeal carcinoma by downregulating the expression of multidrug resistanceassociated protein. Tumour Biol. 2015; 36:4197-202.

Sonnenberg M, van der Kuip H, Haubeis S, Fritz P, Schroth W, Friedel G, Simon W, Mürdter TE, Aulitzky WE. Highly variable response to cytotoxic chemotherapy in carcinomaassociated fibroblasts (CAFs) from lung and breast. BMC Cancer. 2008; 8:364.

Sørensen AL, Reis CA, Tarp MA, Mandel U, Ramachandran K, Sankaranarayanan V, Schwientek T, Graham R, Taylor-Papadimitriou J, Hollingsworth MA, Burchell J, and Clausen H. Chemoenzymatically synthesized multimeric Tn/STn MUC1 glycopeptides elicit cancer-specific anti-MUC1 antibody responses and override tolerance. Glycobiology. 2006; 16:96-107.

Spiro RG. Protein glycosylation: nature, distribution, enzymatic formation, and disease implications of glycopeptide bonds. Glycobiology. 2002; 12:43R-56R.

Stanick D, Schuss A, Mishriki Y, Chao S, Thor A, Lundy J. Reactivity of the monoclonal antibody B72.3 with fetal antigen: correlation with expression of TAG-72 in human carcinomas. Cancer Invest. 1988; 6:279-87.

Stanley P, Schachter H, and T.N., 2009. N-Glycans, in: In: Varki A, Cummings RD, Esko JD, et Al., Editors. Essentials of Glycobiology. 2nd Edition. p. Chapter 8.

Steentoft C, Vakhrushev SY, Joshi HJ, Kong Y, Vester-Christensen MB, Schjoldager KT, Lavrsen K, Dabelsteen S, Pedersen NB, Marcos-Silva L, Gupta R, Bennett EP, Mandel U, Brunak S, Wandall HH, Levery SB, and Clausen H. Precision mapping of the human OGalNAc glycoproteome through SimpleCell technology. EMBO J. 2013; 32:1478-88.

Steentoft C, Vakhrushev SY, Vester-Christensen MB, Schjoldager KT, Kong Y, Bennett EP, Mandel U, Wandall H, Levery SB, Clausen H. Mining the O-glycoproteome using zincfinger nuclease-glycoengineered SimpleCell lines. Nat Methods. 2011; 8:977-82.

Stewart DJ. Mechanisms of resistance to cisplatin and carboplatin. Crit Rev Oncol Hematol 2007; 63:12-31.

Su M, Ge L, Ge S, Li N, Yu J, Yan M, Huang J. Paper-based electrochemical cyto-device for sensitive detection of cancer cells and in situ anticancer drug screening. Anal Chim Acta. 2014; 847:1-9. 
Su W, Huang L, Ao Q, Zhang Q, Tian X, Fang Y, Lu Y. Noscapine sensitizes chemoresistant ovarian cancer cells to cisplatin through inhibition of HIF-1 $\alpha$. Cancer Lett. 2011; 305:949.

Sun JM, Sung JY, Park SH, Kwon GY, Jeong BC, Seo SI, Jeon SS, Lee HM, Jo J, Choi HY, Lim HY. ERCC1 as a biomarker for bladder cancer patients likely to benefit from adjuvant chemotherapy. BMC Cancer. 2012; 12:187.

Sun XP, Dong X, Lin L, Jiang X, Wei Z, Zhai B, Sun B, Zhang Q, Wang X, Jiang H, Krissansen GW, Qiao H, Sun X. Up-regulation of survivin by AKT and hypoxia-inducible factor $1 \alpha$ contributes to cisplatin resistance in gastric cancer. FEBS J. 2014; 281:115-28.

Tadini-Buoninsegni F, Bartolommei G, Moncelli MR, Inesi G, Galliani A, Sinisi M, Losacco M, Natile G, Arnesano F. Translocation of platinum anticancer drugs by human copper ATPases ATP7A and ATP7B. Angew Chem Int Ed Engl. 2014; 53:1297-301.

Tagscherer KE, Fassl A, Campos B, Farhadi M, Kraemer A, Böck BC, Macher-Goeppinger S, Radlwimmer B, Wiestler OD, Herold-Mende C, and Roth W. Apoptosis-based treatment of glioblastomas with ABT-737, a novel small molecule inhibitor of Bcl-2 family proteins. Oncogene. 2008; 27:6646-56.

Takahashi M, Koi M, Balaguer F, Boland CR, Goel A. MSH3 mediates sensitization of colorectal cancer cells to cisplatin, oxaliplatin, and a poly(ADP-ribose) polymerase inhibitor. J Biol Chem. 2011; 286:12157-65.

Takahashi R, Markovic SN, and Scrable HJ. Dominant effects of $\Delta 40 \mathrm{p} 53$ on p53 function and melanoma cell fate. J Invest Dermatol. 2014;134:791-800.

Takenaka Y, Fukumori T, Yoshii T, Oka N, Inohara H, Kim HR, Bresalier RS, and Raz A. Nuclear Export of Phosphorylated Galectin-3 Regulates Its Antiapopt ic Activity in Response to Chemotherapeutic Drugs. Mol Cell Biol. 2004; 24:4395-406.

Tanida S, Mizoshita T, Ozeki K, Tsukamoto H, Kamiya T, Kataoka H, Sakamuro D, and Joh T. Mechanisms of cisplatin-induced apoptosis and of cisplatin sensitivity: Potential of BIN1 to act as a potent predictor of cisplatin sensitivity in gastric cancer treatment. Int J Surg Oncol. 2012; 2012:862879.

Taniguchi N, Kizuka Y. Glycans and cancer: role of N-glycans in cancer biomarker, progression and metastasis, and therapeutics. Adv Cancer Res. 2015; 126:11-51.

Terao N, Takamatsu S, Minehira T, Sobajima T, Nakayama K, Kamada Y, Miyoshi E. Fucosylation is a common glycosylation type in pancreatic cancer stem cell-like phenotypes. World J Gastroenterol. 2015; 21:3876-87.

Terraneo L, Avagliano L, Caretti A, Bianciardi P, Tosi D, Bulfamante GP, Samaja M, Trinchera M. Expression of carbohydrate-antigen sialyl-Lewis a on colon cancer cells promotes xenograft growth and angiogenesis in nude mice. Int J Biochem Cell Biol. 2013; 45:2796800.

Testa R, Vanhooren V, Bonfigli AR, Boemi M, Olivieri F, Ceriello A, Genovese S, Spazzafumo L, Borelli V, Bacalini MG, Salvioli S, Garagnani P, Dewaele S, Libert C, Franceschi C. NGlycomic Changes in Serum Proteins in Type 2 Diabetes Mellitus Correlate with 
Complications and with Metabolic Syndrome Parameters. PLoS One. 2015; 10:e0119983.

Thor A, Ohuchi N, Szpak CA, Johnston WW, and Schlom J. Distribution of oncofetal antigen tumor-associated glycoprotein-72 defined by monoclonal antibody B72.3. Cancer Res. 1986; 46:3118-24.

Tirino V, Desiderio V, Paino F, De Rosa A, Papaccio F, La Noce M, Laino L, De Francesco F, and Papaccio G. Cancer stem cells in solid tumors: an overview and new approaches for their isolation and characterization. FASEB J. 2013; 27:13-24.

Topping RP, Wilkinson JC, Scarpinato KD. Mismatch repair protein deficiency compromises cisplatin-induced apoptotic signaling. J Biol Chem. 2009; 284:14029-39.

Torre C, Wang SJ, Xia W, Bourguignon LYW. Hyaluronan-CD44-mediated growth, migration, and cisplatin resistance in head and neck cancer due to inhibition of Rho kinase and PI-3 kinase signaling. Arch Otolaryngol Head Neck Surg. 2010; 136:493-501.

Tozawa K, Okamoto T, Kawai N, Hashimoto Y, Hayashi Y, and Kohri K. Positive correlation between sialyl Lewis $\mathrm{X}$ expression and pathologic findings in renal cell carcinoma. Kidney Int. 2005; 67:1391-6.

Tripathi M, Billet S and Bhowmick NA. Understanding the role of stromal fibroblasts in cancer progression. Cell Adh. Migr. 2012; 6:231-235.

Trzaska S. Cisplatin. Chem. Eng. News. 2005; 83:1-162.

Tsuboi K, Shimura T, Masuda N, Ide M, Tsutsumi S, Yamaguchi S, Asao T, and Kuwano H. Galectin-3 expression in colorectal cancer: relation to invasion and metastasis. Anticancer Res. 2007; 27:2289-96.

Turner NC and Tutt AN. Platinum chemotherapy for BRCA1-related breast cancer: do we need more evidence? Breast Cancer Res. 2012; 14:115.

van Oosterwijk JG, Herpers B, Meijer D, Briaire-de Bruijn IH, Cleton-Jansen AM, Gelderblom $\mathrm{H}$, van de Water $\mathrm{B}$, and Bovée JV. Restoration of chemosensitivity for doxorubicin and cisplatin in chondrosarcoma in vitro: BCL-2 family members cause chemoresistance. Ann Oncol. 2012; 23:1617-26.

Varki A, Kannagi R, and Toole BP, 2009. Glycosylation Changes in Cancer., in: In: Varki A, Cummings RD, Esko JD, et Al., Editors. Essentials of Glycobiology. 2nd Edition. p. Chapter 44 .

Varma RR, Hector SM, Clark K, Greco WR, Hawthorn L, Pendyala L. Gene expression profiling of a clonal isolate of oxaliplatin-resistant ovarian carcinoma cell line A2780/C10. Oncol. Rep. 2005; 14:925-32.

Velasco A, Corvalan A, Wistuba II, Riquelme E, Chuaqui R, Majerson A, Leach FS. Mismatch repair expression in testicular cancer predicts recurrence and survival. Int J Cancer. 2008; 122:1774-7.

Verhaak RGW, Tamayo P, Yang J, Hubbard D, Zhang H, Creighton CJ, Fereday S, Lawrence M, Carter SL, Mermel CA, Kostic AD, Etemadmoghadam D, Sakse G, Zhang Y, Akbani R, Hoadley KA, Kahn A, Köbel M, Huntsman D, Soslow RA, Defazio A, Birrer MJ, Gray 
JW, Weins. Prognostically relevant gene signatures of high-grade serous ovarian carcinoma. J. Clin. Invest. 2012; 123:517-25.

Videira PA, Correia M, Malagolini N, Crespo HJ, Ligeiro D, Calais FM, Trindade H, and Dall'Olio F. ST3Gal.I sialyltransferase relevance in bladder cancer tissues and cell lines. BMC Cancer. 2009; 9:357.

Visvader JE and Lindeman GJ. Cancer stem cells in solid tumours: accumulating evidence and unresolved questions. Nat Rev Cancer. 2008; 8:755-68.

Wang HQ, Jin JJ, Wang J. Arctigenin enhances chemosensitivity to cisplatin in human nonsmall lung cancer $\mathrm{H} 460$ cells through downregulation of survivin expression. J Biochem Mol Toxicol. 2014; 28:38-45.

Wang L, Wei J, Qian X, Yin H, Zhao Y, Yu L, Wang T, Liu B. ERCC1 and BRCA1 mRNA expression levels in metastatic malignant effusions is associated with chemosensitivity to cisplatin and/or docetaxel. BMC Cancer. 2008; 8:97.

Wang QE, Milum K, Han C, Huang YW, Wani G, Thomale J, Wani AA. Differential contributory roles of nucleotide excision and homologous recombination repair for enhancing cisplatin sensitivity in human ovarian cancer cells. Mol Cancer. 2011; 10:24.

Wang W, Quan Y, Fu Q, Liu Y, Liang Y, Wu J, Yang G, Luo C, Ouyang Q, Wang Y. Dynamics between cancer cell subpopulations reveals a model coordinating with both hierarchical and stochastic concepts. PLoS One. 2014; 9:e84654.

Weisz L, Oren M, Rotter V. Transcription regulation by mutant p53. Oncogene. 2007; 26:22022211.

Whittle JR, Lewis MT, Lindeman GJ and Visvader JE. Patient-derived xenograft models of breast cancer and their predictive power. Breast Cancer Res. 2015; 17:17.

Wiedemeyer WR, Beach JA and Karlan BY. Reversing Platinum Resistance in High-Grade Serous Ovarian Carcinoma: Targeting BRCA and the Homologous Recombination System. Front Oncol. 2014; 4:34.

Williams SA, Anderson WC, Santaguida MT and Dylla SJ. Patient-derived xenografts, the cancer stem cell paradigm, and cancer pathobiology in the 21 st century. Lab. Investig. 2013; 93:970-82.

Wilson WR and Hay MP. Targeting hypoxia in cancer therapy. Nat. Rev. Cancer. 2011; 11:393-410.

Wu W, Koike A, Takeshita T and Ohta T. The ubiquitin E3 ligase activity of BRCA1 and its biological functions. Cell Div. 2008; 3:1.

Wülfing C, van Ahlen H, Eltze E, Piechota H, Hertle L, Schmid KW. Metallothionein in bladder cancer: correlation of overexpression with poor outcome after chemotherapy. World J Urol. 2007; 25:199-205.

Xu X, Duan L, Zhou B, Ma R, Zhou H, Liu Z. Genetic polymorphism of copper transporter protein 1 is related to platinum resistance in Chinese non-small cell lung carcinoma patients. Clin Exp Pharmacol Physiol. 2012; 39:786-92. 
Yamamoto M, Tsujinaka T, Shiozaki H, Doki Y, Tamura S, Inoue M, Hirao M, Monden M. Metallothionein expression correlates with the pathological response of patients with esophageal cancer undergoing preoperative chemoradiation therapy. Oncology. 1999; $56: 332-7$.

Yang CH, Wang HL, Lin YS, Kumar KP, Lin HC, Chang CJ, Lu CC, Huang TT, Martel J, Ojcius DM, Chang YS, Young JD, Lai HC. Identification of CD24 as a cancer stem cell marker in human nasopharyngeal carcinoma. PLoS One. 2014; 9:e99412.

Yang GY, Malik NK, Chandrasekhar R, Ma WW, Flaherty L, Iyer R, Kuvshinoff B, Gibbs J, Wilding G, Warren G, May KS. Change in CA 19-9 levels after chemoradiotherapy predicts survival in patients with locally advanced unresectable pancreatic cancer. J Gastrointest Oncol. 2013; 4:361-9.

Yasuda K, Torigoe T, Morita R, Kuroda T, Takahashi A, Matsuzaki J, Kochin V, Asanuma H, Hasegawa T, Saito T, Hirohashi Y, Sato N. Ovarian cancer stem cells are enriched in side population and aldehyde dehydrogenase bright overlapping population. PLoS One. 2013; 8:e68187.

Ychou M, Duffour J, Kramar A, Gourgou S, and Grenier J. Clinical significance and prognostic value of CA72-4 compared with CEA and CA19-9 in patients with gastric cancer. Dis Markers. 2000; 16:105-10.

Yonezawa A, Masuda S, Yokoo S, Katsura T, Inui K. Cisplatin and Oxaliplatin, but not Carboplatin and Nedaplatin, are substrates for human organic cation transporters ( SLC22A1 - 3 and multidrug and toxin extrusion family). J Pharmacol Exp Ther. 2006; 319:879-86.

Yoshizawa K, Nozaki S, Kitahara H, Ohara T, Kato K, Kawashiri S, Yamamoto E. Copper efflux transporter (ATP7B) contributes to the acquisition of cisplatin-resistance in human oral squamous cell lines. Oncol. Rep. 2007; 18:987-91.

Yuan L, Yu WM, and Qu CK. DNA Damage-induced G2/M Checkpoint in SV40 Large T Antigen-immortalized Embryonic Fibroblast Cells Requires SHP-2 Tyrosine Phosphatase. J Biol Chem. 2003; 278:42812-20.

Yuan M, Luong P, Hudson C, Gudmundsdottir K, Basu S. c-Abl phosphorylation of $\Delta \mathrm{Np} 63 \alpha$ is critical for cell viability. Cell Death Dis. 2010; 1:e16.

Zhang H, Bosch-Marce M, Shimoda LA, Tan Y, JBaek JH, Wesley JB, Gonzalez FJ, and Semenza GL. Mitochondrial autophagy is an HIF-1-dependent adaptive metabolic response to hypoxia. J. Biol. Chem. 2008; 283:10892-903.

Zhang Y, Fonslow BR, Shan B, Baek MC, and Yates JR 3rd. Protein analysis by shotgun/bottom-up proteomics. Chem Rev. 2013; 113:2343-94.

Zhang Y, Wang Z, Yu J, Shi Jz, Wang C, Fu Wh, Chen Zw, Yang J. Cancer stem-like cells contribute to cisplatin resistance and progretion in bladder cancer. Cancer Lett. 2012; $322: 70-7$.

Zhang Z, Zhao Y, Jiang L, Miao X, Zhou H, Jia L. Glycomic alterations are associated with multidrug resistance in human leukemia. Int J Biochem Cell Biol. 2012; 44:1244-53. 
Zhao Y, Bao Q, Schwarz B, Zhao L, Mysliwietz J, Ellwart J, Renner A, Hirner H, Niess H, Camaj P, Angele M, Gros S, Izbicki J, Jauch KW, Nelson PJ, Bruns CJ. Stem cell-like side populations in esophageal cancer: a source of chemotherapy resistance and metastases. Stem Cells Dev. 2014; 23:180-92.

Zhao Y, Li Y, Ma H, Dong W, Zhou H, Song X, Zhang J, Jia L. Modification of Sialylation Mediates the Invasive Properties and Chemosensitivity of Human Hepatocellular Carcinoma. Mol Cell Proteomics. 2014; 13:520-36.

Zhao Y, Sato Y, Isaji T, Fukuda T, Matsumoto A, Miyoshi E, Gu J, and Taniguchi N. Branched $\mathrm{N}$-glycans regulate the biological functions of integrins and cadherins. FEBS J. 2008; 275:1939-48.

Ziske C, Schlie C, Gorschlüter M, Glasmacher A, Mey U, Strehl J, Sauerbruch T, and SchmidtWolf IG. Prognostic value of CA 19-9 levels in patients with inoperable adenocarcinoma of the pancreas treated with gemcitabine. Br J Cancer. 2003; 89:1413-17.

Zöller M. CD44, Hyaluronan, the Hematopoietic Stem Cell, and Leukemia-Initiating Cells. Front Immunol. 2015; 6:235. 